\title{
Redox condition in molten salts and solute behavior: A first- principles molecular dynamics study
}

\author{
Hyo On Nam, Dane Morgan* \\ Department of Materials Science and Engineering, University of Wisconsin-Madison, Madison, \\ Wisconsin 53706, USA
}

\begin{abstract}
Molten salts technology is of significant interest for nuclear, solar, and other energy systems. In this work, first-principles molecular dynamics (FPMD) was used to model the solute behavior in eutectic $\mathrm{LiCl}-\mathrm{KCl}$ and $\mathrm{FLiBe}\left(\mathrm{Li}_{2} \mathrm{BeF}_{4}\right)$ melts at $773 \mathrm{~K}$ and $973 \mathrm{~K}$, respectively. The thermokinetic properties for solute systems such as the redox potential, solute diffusion coefficients and structural information surrounding the solute were predicted from FPMD modeling and the calculated properties are generally in agreement with the experiments. In particular, we formulate an approach to model redox energetics vs. chlorine (or fluorine) potential from firstprinciples approaches. This study develops approaches for, and demonstrates the capabilities of, FPMD to model solute properties in molten salts.
\end{abstract}

*Corresponding author

Dane Morgan

Associate Professor,

Department of Materials Science and Engineering,

University of Wisconsin-Madison, Madison, Wisconsin 53706

Email: ddmorgan@wisc.edu 


\section{Introduction}

Molten salts, potentially containing dissolved solutes, are of relevance for applications including solar and nuclear system heat transfer [1-5], chemical processing [6-8], and materials synthesis [9-11]. This work is particularly motivated by molten salt applications for nuclear applications. Specifically, we will focus on $\mathrm{LiCl}-\mathrm{KCl}$ and $\mathrm{FLiBe}$ (or just "flibe") salts. Molten LiCl-KCl eutectic salt $(58 \mathrm{~mol} \% \mathrm{LiCl}, 42 \mathrm{~mol} \% \mathrm{KCl})$ is used as an electrolyte and solvent in pyrochemical processing (in short, pyroprocessing) for partitioning (separating of elements) of spent nuclear fuels [1-3]. Pyroprocessing of spent nuclear fuels in eutectic $\mathrm{LiCl}-\mathrm{KCl}$ has been developed to recycle the fuels and reduce the toxicity/volume of disposable nuclear waste. Most countries are now pursuing a closed fuel cycle and hence the importance of pyroprocessing research is growing. Fluoride salts (FLiBe, FLiNaK, etc.) are being considered as a heat transfer coolants in nuclear reactor systems such as molten salt reactor (MSR) [6] and fluoride-saltcooled high-temperature reactor (FHR) [7-8].

Solute behavior is of critical importance in both the salts being studied in this work. In pyropocessing, solutes behavior controls the element partitioning processes. To control and model these processes it is essential to start with accurate data on the thermochemical properties of solutes in the molten salt. However, the desired data are often not available, either due to there being no experimental studies or the existing studies showing a large scatter due to the different experimental conditions (e.g., temperature, concentration of solute, reference electrode, etc.). Similarly, corrosion is a major concern for flibe applications [12-14] and solute properties are essential to understanding how compounds dissolve through corrosion into the salt. In particular, corrosion behavior of structural materials in fluoride salt is governed mainly by solute redox potentials and the fluorine potential in the salt [15].

In previous studies [16-17], the FPMD approach for modeling molten salt properties was validated by estimating the basic properties of pure $\mathrm{LiCl}-\mathrm{KCl}$ and flibe salts (density, bulk modulus, coefficient of thermal expansion, structural information and self-diffusivities of constituents) and comparing these values with published experimental data. Building on these validations of the pure salt FPMD simulations, we focus here on extending the approaches to modeling solute behaviors in molten $\mathrm{LiCl}-\mathrm{KCl}$ and flibe salts. Although we focus on the modeling of solute behaviors in just two specific molten salts, the FPMD approaches used here can also be used for the study of a wide range of molten salt systems.

The objective of this study is developing approaches to modeling the solute behavior in molten salts for both increased understanding of solvation processes and generating essential thermochemical data for solutes. These data can then be used for the modeling of partitioning processes and chemistry control for FHR systems. We focus here on the use of quantum mechanical first principles molecular dynamics (FPMD) methods. While these methods are computationally demanding compared to interatomic potential molecular dynamics, they do not 
require or rely on fitted potentials which may enable more accurate simulations and easier application to a wide range of chemistries. In particular, we here focus on developing the formalism for modeling multiple redox states of impurities.

\section{Computational methods}

\subsection{Details of first-principles molecular dynamics simulation}

In the simulation of molten salts system, ionic position were pre-equilibrated with the classical interatomic potential molecular dynamics (IPMD) simulations to facilitate the equilibration of the system. Packmol [18] was used to pack atoms in the simulation box randomly then LAMMPS [19] was used for the IPMD simulations. In the IPMD simulations, Born-MeyerHuggins (or Tosi-Fumi) type potentials [20-22] were used with the parameters taken from the references for pure $\mathrm{LiCl}-\mathrm{KCl}$ [23] and flibe [24], respectively. Potential parameters for dissolved solutes in molten salts were approximated based on the formulation detailed in Larsen et al. [25]. We note that this includes only the pair potential portion of the complete potentials used in Refs. [23] and [24] and therefore will not be highly accurate. However, these IPMD structures are used only to initiate the FPMD runs and therefore do not need to be highly accurate. Detailed procedures for geometry equilibration using IPMD were addressed in the previous study [16-17].

With the pre-equilibrated system, first-principles molecular dynamics (FPMD) simulations were performed via density functional theory (DFT) as implemented in the Vienna Ab-Initio Simulation Package (VASP) version 5.3.2 [26-28] in the generalized gradient approximation (GGA) using the Perdew-Burke-Ernzerhof (PBE) exchange-correlation functional [29-30]. Constant number-volume-temperature (NVT) simulations were used with projector augmented wave (PAW) technique and a plane wave basis set with an energy cutoff of $600 \mathrm{eV}$. As discussed in the previous study [17], PBE potential with the vdW-DF dispersion term (vdW-optB88) [31] were chosen to be used in the simulation because it gives a closest match with the experimental equilibrium volume of molten salts. A $1 \times 1 \times 1 \mathrm{k}$-point mesh was used in the simulation because it is computationally tractable and the difference in energy of a test system (total 66 atoms, flibe with $\mathrm{CrF}_{2}$ ) between $1 \times 1 \times 1$ and $4 \times 4 \times 4$ kpoint meshes was less than $1 \mathrm{meV} /$ atom. A one femtosecond (fs) time step is used. Energy drift of the simulations was less than 2meV/atom-ps. Although pure salts are non-magnetic, all calculations with the solute ions were conducted with spin-polarization because the solute typically has a magnetic moment. Magnetic moments of the solute atoms and ions were stable throughout the simulation [17]. Before getting averaged thermo-kinetic properties of solutes in the salts from the FPMD simulations, more than 4ps FPMD runs were performed for each solute-solvent system for a further equilibration in the properties of the solute in the system even after the IPMD pre-equilibration. 
In the simulations, a cell with 64 atoms with a eutectic composition of $\mathrm{LiCl}-\mathrm{KCl}$ (19 $\mathrm{Li}$ atoms, $13 \mathrm{~K}$ atoms, $32 \mathrm{Cl}$ atoms; $59.4 \% \mathrm{LiCl}$ ) was used for pure $\mathrm{LiCl}-\mathrm{KCl}$ salt and a cell with 63 atoms containing seven formula unit of $\mathrm{Li}_{2} \mathrm{BeF}_{4}(18 \mathrm{Li}$ atoms, $9 \mathrm{Be}$ atoms, $36 \mathrm{~F}$ atoms) was used for the pure flibe salt. For the modeling of solutes in molten salts, solute atoms with the excess anions were added in the simulation cell. For example, $\mathrm{U}, \mathrm{UCl}_{3}$ and $\mathrm{UCl}_{4}$ were added to the 64 atoms of the $\mathrm{LiCl}-\mathrm{KCl}$ cell to simulate a $\mathrm{U}^{0}, \mathrm{U}^{3+}$ and $\mathrm{U}^{4+}$, respectively.

For the modeling of solutes in molten salts, eight different solute species ( $\mathrm{Li}, \mathrm{Sr}, \mathrm{La}, \mathrm{Nd}, \mathrm{Ce}, \mathrm{Zr}$, $\mathrm{U}$ and $\mathrm{Eu}$ ) in $\mathrm{LiCl}-\mathrm{KCl}$ and five different solute species ( $\mathrm{Li}, \mathrm{Be}, \mathrm{Zr}, \mathrm{Fe}$ and $\mathrm{Cr}$ ) in flibe were simulated. These elements are chosen to include a range of redox values, elements with experimental data for validation, elements associated with pyroprocessing (e.g., lanthanides and actinides in $\mathrm{LiCl}-\mathrm{KCl}$ ), and elements associated with corrosion ( $\mathrm{Fe}, \mathrm{Cr}$ in flibe). In order to observe the effect of the ionization of the solutes, both neutral atom and solute ion are considered. These simulations therefore involve 18 systems ( $\mathrm{Li}(\mathrm{I}), \mathrm{Li}(0), \mathrm{Sr}(\mathrm{II}), \mathrm{Sr}(0), \mathrm{La}(\mathrm{III}), \mathrm{La}(0), \mathrm{Nd}(\mathrm{III})$, $\mathrm{Nd}(0), \mathrm{Ce}(\mathrm{III}), \mathrm{Ce}(0), \mathrm{Zr}(\mathrm{IV}), \mathrm{Zr}(0), \mathrm{U}(\mathrm{IV}), \mathrm{U}(\mathrm{III}), \mathrm{U}(0), \mathrm{Eu}(\mathrm{III}), \mathrm{Eu}(\mathrm{II}), \mathrm{Eu}(0))$ for LiCl-KCl and 12 systems (Li(I), Li(0), Be(II), Be(0), Zr(IV), Zr(0), Fe(III), Fe(II), Fe(0), Cr(III), Cr(II), Cr(0)) for flibe. The PAW-PBE potentials that were used in this study for $\mathrm{LiCl} \_\mathrm{KCl}$ are $\mathrm{Li} \_\mathrm{sv}\left(1 \mathrm{~s}^{2} 2 \mathrm{~s}^{1}\right)$, K_sv $\left(3 s^{2} 3 p^{6} 4 s^{1}\right)$ and $\mathrm{Cl}\left(3 s^{2} 3 p^{5}\right)$. Valence electrons for each element are specified within parenthesis. For flibe, Li_sv, Be $\left(2 s^{2}\right)$ and $\mathrm{F}\left(2 s^{2} 2 p^{5}\right)$ were used. For dissolved solutes in molten salts, Sr_sv $\left(4 s^{2} 4 p^{6} 5 s^{2}\right)$, La_s $\left(4 p^{6} 5 s^{2} 6 d^{1}\right), N d \_3\left(5 s^{2} 5 p^{6} 4 f^{3}\right), C e\left(5 s^{2} 5 p^{6} 6 s^{2} 4 f^{2}\right), Z r \_s v$ $\left(4 s^{2} 4 p^{6} 5 s^{2} 4 d^{2}\right)$, U_s $\left(6 s^{2} 6 p^{6} 7 s^{2} 5 f^{4}\right), E u\left(5 s^{2} 5 p^{6} 6 s^{2} 4 f^{7}\right), F e\left(3 d^{7} 4 s^{1}\right)$ and Cr_pv $\left(3 p^{6} 3 d^{5} 4 s^{1}\right)$ were used.

In this study, temperature effects are not explored in detail and only one temperature for each salt system was used. For the $\mathrm{LiCl}-\mathrm{KCl}$ salt, $773 \mathrm{~K}\left(500^{\circ} \mathrm{C}\right)$ is chosen because it is a typical operating temperature of the electro-refining system in pyroprocessing [1-2]. For the flibe salt, 973K $\left(700^{\circ} \mathrm{C}\right)$ was chosen, as this is the typical operating coolant temperature being considered for fluoride-salt-cooled reactor systems [7-8].

The standard error of the mean for steady-state system parameters (temperature, pressure, energy, etc.) from correlated molecular dynamics steps was estimated using an auto-covariance function. Eq. (1), which was taken from reference [32], defines the variance of the sample mean $\left(\operatorname{Var}\left(\bar{X}_{n}\right)\right)$ of a series of $n$ molecular dynamics (MD) data values $\left(X_{1}, X_{2}, \ldots, X_{n}\right)$ in terms of the auto-covariance function $\left(R_{j}=\operatorname{Cov}\left(X_{t}, X_{t+j}\right)=E\left[\left(X_{t}-\mu\right)\left(X_{t+j}-\mu\right)\right], \mathrm{j}=0, \pm 1, \pm 2, \ldots\right)$ with the usual notation $E$ for the expectation operator and the mean function $\mu=E\left[X_{t}\right]$. The covariance gives the autocorrelation of $X_{t}$ with itself $j$ steps later.

$$
\operatorname{Var}\left(\bar{X}_{n}\right)=\frac{1}{n}\left[\sigma_{X}^{2}+2 \sum_{j=1}^{n-1}(1-j / n) R_{j}\right]
$$


Typically the values of $X$ are sampled every time step in the MD simulation.

\subsection{Computational strategies}

For the simulations of solute systems, we employed certain strategies in order to calculate solute properties accurately with a reasonable amount of computational cost. In the case of the pure salts, multiple atoms for the same species are in the cell and this helps to calculate accurate average properties from limited length of FPMD simulations. However, in case of the solute systems, more extensive statistical average of properties must be pursued because only one solute atom is being sampled.

Solute properties were determined by nine independent simulations for 4-8ps conducted for each solute system. To assess if this sampling is adequate, convergence of the diffusion coefficient of solute in molten salts was tested with the IPMD for a long time (1ns) with 1000 atoms to obtain an essentially exact result. These tests showed that nine independent simulations for 4 ps duration are enough to predict the mean diffusion coefficients of a solute, and its estimated standard deviation in that mean, with enough accuracy that the predicted mean value was reliably within two standard deviations of the highly converged result from the very long IPMD run. As the standard deviations in the mean were relatively small and gave meaningful errors bars on the mean value, we took this sampling to be adequate for the diffusion calculations. We then assumed that the energy of the system was also adequately converged by such sampling.

All FPMD calculations were given an effective initial equilibration of $>4 \mathrm{ps}$ for each solute. These equilibration runs were done after the IPMD and before any of the production runs of FPMD discussed in this paper and from which data is was taken. These equilibration runs were actually done using a series of different exchange correlation functionals (specifically, PBE [2930] without the vdW-DF dispersion term and PBEsol [33]) to assess their potential effects. While this is not the traditional method of doing equilibration (equilibration is generally done with the same method used in production runs) the large computational expense of these calculations forced us to combine equilibration and testing of exchange-correlation functionals. We believe that the variations in structure associated with the relatively similar exchangecorrelation functionals we explored is small enough that this approach will provide an effective equilibration. The equilibration was then assessed by an explicit test of the convergence of the coordination number values. In the Cr solute-solvent coupled systems, nine simulations for 8ps were performed. Coordination numbers were then found for the data averaged over all nine simulations from their first $4 \mathrm{ps}$ and then separately from their second $4 \mathrm{ps}$. When we compare these coordination numbers they were identical to within a standard deviation of 0.2 for the neutral $\mathrm{Cr}$ and 0.1 for the $\mathrm{Cr}^{2+}$ and $\mathrm{Cr}^{3+}$, respectively. This result strongly suggest that the values are well converged to within a reasonable error. 
The cell volumes for salts with each solute ion were estimated to avoid recalculating the equilibrium volume for each new solute system. It is time consuming to determine the equilibrium volume $\left(\mathrm{V}_{0}\right)$ of the molten salts using the approach taken in Refs [16-17] (which use an equation of state (EOS) analysis) for all the 30 different solute containing systems. Equilibrium volume of the solute containing systems was estimated by adding the equilibrium $\mathrm{V}_{0}$ of the pure salt from experiments [34-35] and the volume of the solid solute chlorides (or fluorides), which was calculated from DFT [36]. For example, for $\mathrm{U}^{3+}$ simulation in $\mathrm{LiCl}-\mathrm{KCl}$, the volume would be the sum of that for pure $\mathrm{LiCl}-\mathrm{KCl}$ salt and solid $\mathrm{UCl}_{3}$.

To estimate the effect of having only an approximate volume on the energy we use the equations

$$
\begin{aligned}
& \Delta E=E_{1}-E_{0}=\frac{1}{2} B_{0} \frac{\left(V_{1}-V_{0}\right)^{2}}{V_{0}} \\
& \frac{V_{1}}{V_{0}}=\exp \left(-\frac{P_{1}}{B_{0}}\right)
\end{aligned}
$$

where $V_{0}$ is the equilibrium volume, $V_{1}$ the estimated volume, $E_{0}$ the energy at $V_{0}, E_{1}$ the energy at $V_{1}, B_{0}$ the bulk modulus, and $P_{1}$ the pressure at $V_{1}$. The pressure of the solute systems with the estimated volume was about $\pm 0.3 \mathrm{GPa}$ on average. Calculated $\Delta E$ due to the $0.3 \mathrm{GPa}$ is about $0.02 \mathrm{eV}$ considering the $B_{0}$ of $10 \mathrm{GPa}$ of flibe $[17,37]$. $\Delta E$ due to the volume estimation for LiCl$\mathrm{KCl}$ solute system is assumed to be of a similar magnitude. This range of error in energy is significantly below that from other sources, e.g. DFT errors and uncertainty from limited sampling, so for this work the estimated volumes are acceptable for our energy calculations.

The effect of volume estimation on the diffusion coefficient was also assessed in terms of an activation volume $\left(V_{a}\right)[38]$ which is defined in Eq. (4).

$$
D_{1}=D_{e q} \cdot \exp \left(-P_{1} V_{a} / k T\right)
$$

where $D_{e q}$. the diffusion coefficient at the equilibrium volume, $D_{1}$ the diffusivity at $P_{1}, k$ Boltzmann constant, $T$ the temperature in Kelvin. The shift of the diffusion coefficient due to the pressure offset of $0.3 \mathrm{GPa}$ is calculated to be about $2 \%$ of $D_{\text {eq }}$. based on the estimated activation volume for diffusion of $\mathrm{Li}$ ion in pure flibe at $973 \mathrm{~K}$, which is about $0.04 \mathrm{~cm}^{3} / \mathrm{mol}$. The activation volume for diffusion was estimated from the pressure-dependent self-diffusion data based on the Eq. (4) [39]. Again, this error in $D_{e q}$ is quite small compared to the uncertainty associated with limited sampling, justifying the use of the estimated volumes.

\subsection{Formulation for redox potentials in molten salts from FPMD simulations}


In this study, redox (reduction-oxidation) potentials of various redox couples in molten salts were calculated from FPMD simulations following the general electrochemical referencing approach developed by Nørskov and collaborators [40]. Conventionally, reduction reactions are chosen to assess the redox reaction as shown in the example for the $\mathrm{U}(\mathrm{IV}) / \mathrm{U}(\mathrm{III})$ redox reaction (Eq.(5)).

$\mathrm{UCl}_{4}$ dissolved in salt $=\mathrm{UCl}_{3 \text { dissolved in salt }}+0.5 \mathrm{Cl}_{2}(\mathrm{~g})$

The $\mathrm{Cl}_{2}$ gas is assumed to be at the temperature where the redox value is being measured and 1 atm pressure. Based on the above reactions, the redox potential for U(IV)/U(III) couple was calculated using Eq. (6),

$$
\left\langle V_{\text {redox }}\right\rangle_{U C l_{4} / U C l_{3}}\left(v s . C l_{2} / C l^{-}\right)=-\frac{\left[\left\langle E\left(U C l_{3}+M S\right)\right\rangle+0.5 \cdot G\left(C l_{2}\right)-\left\langle E\left(U C l_{4}+M S\right)\right\rangle\right]+C^{S}}{1 \cdot e}
$$

where MS denotes the molten salt, $\langle E\rangle$ the ensemble average of total energy as calculated from FPMD, $e$ the absolute value of the electron charge, $G\left(\mathrm{Cl}_{2}\right)$ the free energy of a chlorine gas at the temperature of the calculation and one atmospheric pressure [41-42], and $C^{S}$ the entropy correction term [43]. This term includes the entropy contributions for the dissolved chlorides because the energy from the FPMD does not include the entropic contributions in it. Ideally $C^{S}$ would also be calculated from the FPMD, but as this is not practical with reasonable computational resources. $C^{S}$ is assumed to be same as the entropy of the solid phase solute chloride (e.g., $\mathrm{UCl}_{3}$ ) or fluoride (e.g., $\mathrm{CrF}_{2}$ ), as shown in Eq. (7).

$C^{S}=-\left(T \cdot S_{U C l_{3}}^{\text {solid }}-T \cdot S_{U C l_{4}}^{\text {solid }}\right) / F$

where $S$ is the entropy of the solid phase solute chloride, $T$ the temperature and $F$ the Faraday constant. Values of $C^{S}$ can be obtained from thermodynamic databases [43].

We note for clarification that when a redox reaction between the neutral metal $\left(\mathrm{M}^{0}\right)$ and metal chloride $\left(\mathrm{MCl}_{\mathrm{n}}\right)$ (or fluoride, $\mathrm{MF}_{\mathrm{n}}$ ) is considered the neutral metal occurs in the salt and not in the condensed phase. The free energy of the redox reaction to form the oxidized metal in the salt from the neutral metal in the salt will therefore be different from that for the redox reaction to form the oxidized metal in the salt from the condensed phase, even though both reactions include a neutral metal state. Furthermore, we note that the description of the neutral metals as neutral and denoted as $\mathrm{M}^{0}$ is a statement about how they are introduced into the salt (i.e., without any compensating anions), and does not necessarily describe their valence state. In fact, it is expected that many metals with ionize and donate their electrons to the salt. The fate of these donated electrons can be quite complex, and include forming a localized solvated electron, "bipolaron complexes", as well as percolating paths of solvated electrons and an associated 
metallization of the salt, as simulated previously with FPMD methods by Silvestrelli, et al. [44]. Given the uncertainties of electronic localization properties within DFT and the GGA approximations used here, as well as associated factors relating to concentration, cell size, and determining ground state polaron arrangements, a detailed study of the electrons donated from the neutral atoms is beyond the scope of this paper. We have simply allowed the simulation to equilibrate the electrons and made no effort to force any particular arrangements. While we expect this to yield accurate energetics in most cases, it is possible that some complexities of the neutral atom donated electrons are not well captured, and some errors in the redox relative to the neutral atoms may be introduced. Further studies of the behavior of the neutral atom and its donated electrons in the salt would be of considerable interest.

In this formalism, ensemble average of energy of the simulation cell is used instead of enthalpy by assuming the cell is at equilibrium volume which makes the cell pressure to be zero. Although $P V$ term for the enthalpy can be calculated, it makes a negligible contribution to the overall redox potential for at atmospheric pressure or under the pressures of our estimated volumes. Furthermore, the magnitude of the error in the $P V$ term, which was induced by the large fluctuation of pressure during the MD runs, was quite large. The free energy of the gaseous $\mathrm{Cl}_{2}$ (and $\mathrm{F}_{2}$ for flibe redox reactions) involved in the redox formulation was obtained from semiempirical thermodynamic tables [45] properly referenced to the same reference state as the DFT $\mathrm{Cl}$ (and F) energies, following the approaches in Refs. [41-42]. No corrections to the DFT $\mathrm{Cl}_{2}$ and $\mathrm{F}_{2}$ energies were made. The approach yields an enthalpy of $\mathrm{Cl}_{2}$ and $\mathrm{F}_{2}$ gas at standard temperature and pressure $(300 \mathrm{~K}, 1 \mathrm{~atm})$ relative to the DFT values of $\mathrm{Cl}_{2}$ and $\mathrm{F}_{2}$ of $-1.786 \mathrm{eV} / \mathrm{Cl}$ and $-1.860 \mathrm{eV} / \mathrm{F}$, respectively. From these values the chemical potentials relative to the DFT isolated gas molecules can be readily calculated for any temperature and pressure using the thermodynamics tables [41-42].

The reference reaction (and associated reference potential) for the evaluation of the redox potentials in the $\mathrm{LiCl}-\mathrm{KCl}$ was chosen as a $0.5 \mathrm{Cl}_{2} / \mathrm{Cl}^{-}$, because the redox reaction of $0.5 \mathrm{Cl}_{2} / \mathrm{Cl}^{-}$is already part of the solute redox reaction as shown in the Eq. (5). Many experimental measurements of redox potentials in the $\mathrm{LiCl}-\mathrm{KCl}$ also used a $0.5 \mathrm{Cl}_{2} / \mathrm{Cl}^{-}$reference reaction. For the same reasons, $0.5 \mathrm{~F}_{2} / \mathrm{F}^{-}$was selected as the reference reaction for the redox potentials of solutes in flibe salt.

Note that Eq. (6) gives the relative redox potential for two different charge states in the salt. We will focus on relative redox values in the salt rather than redox from a solid phase to the salt in order to avoid the additional complexities of treating the solid phases and allow us to isolate aspects of the salt thermodynamics and kinetics, which is the focus of this work.

\subsection{Thermo-kinetic properties of solutes in molten salts}


For solutes detailed local structural studies were performed. The radial distribution function (RDF) analysis was conducted from the FPMD trajectory to study the local structure surrounding solute ions in molten salts. The first-shell coordination number of solute ion with the surrounding anions was estimated by integrating the radial distribution function from zero to the first minimum. The neighbor function, which is defined as the integral of the RDF, is shown below,

$$
N_{\alpha \beta}\left(r^{\prime}\right)=4 \pi \cdot \rho_{\beta} \cdot \int_{0}^{r^{\prime}} r^{2} g_{\alpha \beta}(r) d r
$$

where $g_{\alpha \beta}(r)$ is the RDF (see Ref. [46] for definition) between species $\alpha$ and $\beta$, and $\rho_{\beta}$ the average number density of species $\beta$.

The self-diffusion coefficients of solute ions in molten salts were analyzed from the mean square displacement (MSD) of solute ions as a function of time using the Einstein relation shown below,

$$
\begin{aligned}
& M S D=\left\langle\frac{1}{N} \sum_{i=0}^{N}\left(r_{i}\left(t_{0}+d t\right)-r_{i}\left(t_{0}\right)\right)^{2}\right\rangle=\frac{1}{N \cdot n_{t}} \sum_{i=0}^{N} \sum_{j=0}^{n_{t}}\left(r_{i}\left(t_{j}+d t\right)-r_{i}\left(t_{j}\right)\right)^{2} \\
& D=\frac{1}{6} \lim _{t \rightarrow \infty} \frac{d}{d t}(M S D)
\end{aligned}
$$

We note that the analysis of diffusion coefficients using equations (9)-(10) of XDATCAR files from VASP FPMD runs can be readily performed with the MAterials Simulation Toolkit (MAST) Package [47], which can be obtained from https://pypi.python.org/pypi/MAST, and interactively with a corresponding online application available at materialshub.org.

\section{Redox potentials of solutes in molten salts}

In this study, the redox potentials for 10 redox couples in $\mathrm{LiCl}-\mathrm{KCl}$ at $773 \mathrm{~K}$ (see Table 1) and 7 redox couples in flibe (see Table 2) at $973 \mathrm{~K}$ were calculated from the FPMD simulations and compared with the experimental measurements and theoretical predictions from the solid phase redox reactions using a thermodynamic database [43]. The formulation used to calculate the redox potentials is detailed in Section 2.3.

\subsection{Calculated standard reduction potential}

The calculated redox potential of several redox couples in molten $\mathrm{LiCl}-\mathrm{KCl}$ salt at $773 \mathrm{~K}$ from FPMD simulations are compared with the (a) experimentally measured redox potential ( $v s$. 
$\mathrm{Cl}_{2} / \mathrm{Cl}^{-}$reference) and with the (b) predicted redox potential for solid phases of chlorides from the HSC Chemistry [43] (see Fig. 1). Table 1 summarizes the values of the calculated redox potentials and the twice the standard error of the mean (described as $2 \sigma \mathrm{Std}$. Error), experimental measurements, contributions from the entropic correction term $\left(C^{S} / n \cdot e\right.$, where $n$ is the number of electron involved in the reaction), and predicted redox potentials for the redox couples shown in Fig. 1.

Measurements of redox potentials for various solute couples in the $\mathrm{LiCl}-\mathrm{KCl}$ at $723 \mathrm{~K}$ and $773 \mathrm{~K}$ were compiled for the comparison (see Table 1). Published molten salt redox potentials from different researchers and different institutes are averaged and the degree of the scatter of the measurements is quantified as an error bar, which is twice the standard deviation. Some of the data were measured at $723 \mathrm{~K}$ but converted to $773 \mathrm{~K}$ by compensating temperature effect theoretically. To scale redox potentials in the salt to different temperatures it is assumed that the redox change due to the temperature increase is of the same magnitude as the predicted potential change for the solid redox reaction [43].

As the predicted redox potentials were obtained from the reduction reactions of pure solid phase chlorides (e.g., $\mathrm{SrCl}_{2}=\mathrm{Sr}+\mathrm{Cl}_{2}(\mathrm{~g})$ ), the values can be different with the actual measurements of redox reaction in the molten salt. However, these predicted redox values are useful for comparison because they are generally quite close to the potentials measured in the salt.

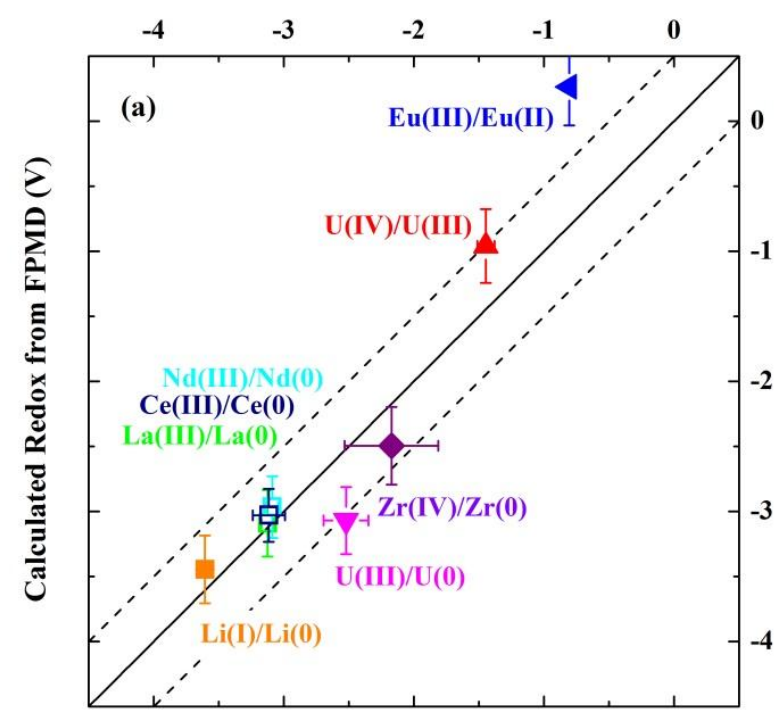

Experimental Redox Potential (V)

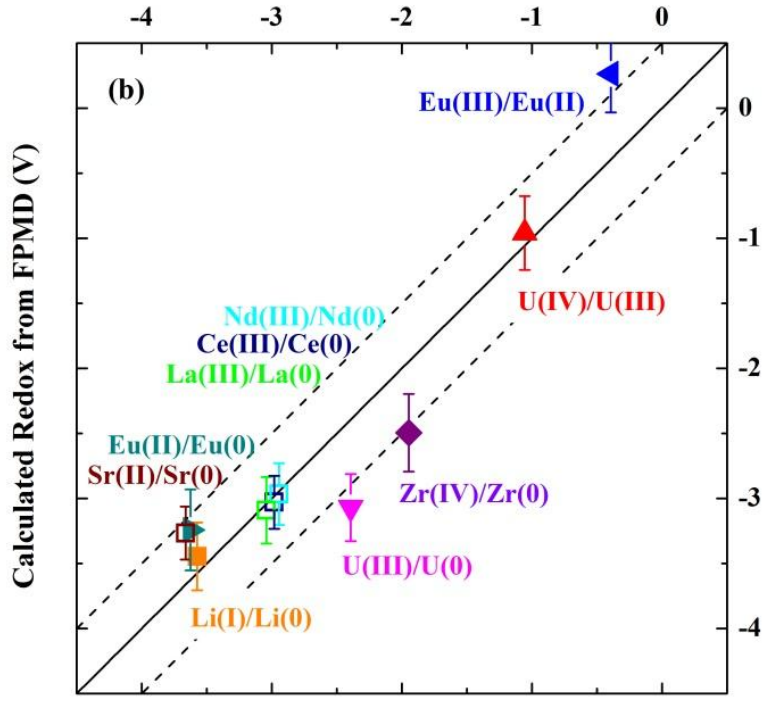

Predicted Redox from HSC (V)

Fig. 1. (a) Comparison of calculated redox potential of several redox couples in molten $\mathrm{LiCl}-\mathrm{KCl}$ salt at 773K by FPMD (y-axis) with the (a) experimental redox potential and the (b) predicted redox potential from the thermodynamic database for pure solid form of chlorides [43]. Dashed lines show $\pm 0.5 \mathrm{~V}$ range from the one-to-one correspondence line. The error bars represent twice 
the standard error of the mean for the calculated redox (or twice the standard deviation for the experimental redox).

Table 1. Calculated redox potential of several redox couples (vs. $\mathrm{Cl}_{2} / \mathrm{Cl}^{-}$reference) in molten $\mathrm{LiCl}$ $\mathrm{KCl}$ salt at $773 \mathrm{~K}$ with the predicted redox potentials from the thermodynamic database [43].

\begin{tabular}{|c|c|c|c|c|c|c|}
\hline Redox couples & $\begin{array}{c}\text { Prediction } \\
\text { from HSC } \\
{[43]} \\
(\mathrm{V})\end{array}$ & $\begin{array}{c}\text { FPMD } \\
\text { this } \\
\text { study) } \\
(\mathrm{V})\end{array}$ & $\begin{array}{c}\text { FPMD } \\
2 \sigma \mathrm{Std} \\
\text { Error } \\
(\mathrm{V})\end{array}$ & $\begin{array}{c}\frac{C^{S}}{n \cdot e} \\
(\mathrm{~V})\end{array}$ & $\begin{array}{c}\text { Experimental } \\
\text { Redox }^{\mathrm{a}} \\
(\mathrm{V})\end{array}$ & References $^{\mathrm{b}}$ \\
\hline $\mathrm{Li}(\mathrm{I}) / \mathrm{Li}(0)$ & -3.574 & -3.445 & 0.261 & 0.378 & $-3.606 \pm 0.062$ & {$[48-49]$} \\
\hline $\mathrm{Sr}(\mathrm{II}) / \mathrm{Sr}(0)$ & -3.663 & -3.266 & 0.204 & 0.441 & - & - \\
\hline $\mathrm{La}(\mathrm{III}) / \mathrm{La}(0)$ & -3.043 & -3.091 & 0.255 & 0.415 & $-3.125 \pm 0.048$ & {$[48,50-55]$} \\
\hline $\mathrm{Nd}(\mathrm{III}) / \mathrm{Nd}(0)$ & -2.946 & -2.967 & 0.238 & 0.417 & $-3.089 \pm 0.046$ & {$[48,51,53$,} \\
& & & & & & $56]$ \\
\hline $\mathrm{Ce}(\mathrm{III}) / \mathrm{Ce}(0)$ & -2.983 & -3.029 & 0.204 & 0.415 & $-3.116 \pm 0.124$ & {$[50-51,53-$} \\
& & & & & & $55]$ \\
\hline $\mathrm{Zr}(\mathrm{IV}) / \mathrm{Zr}(0)$ & -1.946 & -2.494 & 0.299 & 0.472 & $-2.173 \pm 0.360$ & {$[48,57-58]$} \\
\hline $\mathrm{U}(\mathrm{IV}) / \mathrm{U}(\mathrm{III})$ & -1.056 & -0.958 & 0.284 & 0.491 & $-1.446 \pm 0.066$ & {$[48,52,56]$} \\
\hline $\mathrm{U}(\mathrm{III}) / \mathrm{U}(0)$ & -2.393 & -3.069 & 0.258 & 0.477 & $-2.522 \pm 0.174$ & {$[48,50,52$,} \\
& & & & & & $56,59]$ \\
\hline $\mathrm{Eu}(\mathrm{III}) / \mathrm{Eu}(\mathrm{II})$ & -0.394 & 0.265 & 0.296 & 0.308 & $-0.806 \pm 0.016$ & {$[49,60]$} \\
\hline $\mathrm{Eu}(\mathrm{II}) / \mathrm{Eu}(0)$ & -3.625 & -3.241 & 0.312 & 0.423 & - & - \\
\hline
\end{tabular}

${ }^{a}$ Errors are two sigma standard deviation of the experimentally measured redox potentials

${ }^{\mathrm{b}}$ Some of the data were measured at $723 \mathrm{~K}$ and converted to $773 \mathrm{~K}$ by compensating temperature effect theoretically. It is assumed that the redox change due to the temperature increase is of the same magnitude as the predicted potential change for the solid redox reaction from the HSC Chemistry [43].

Fig. 2 shows the comparison of calculated redox potential of several redox couples in molten flibe salt at $973 \mathrm{~K}$ from FPMD with the (a) experimentally measured redox potential (vs. $\mathrm{F}_{2} / \mathrm{F}^{-}$ reference) and the (b) predicted redox potential from the thermodynamic database for solid fluorides [43]. Table 2 summarizes the values of the calculated redox potentials for those couples in molten flibe salt at $973 \mathrm{~K}$ with twice the standard error of the mean (described as $2 \sigma \mathrm{Std}$. Error), experimental measurements, contributions of the entropic correction term, and predicted redox values from HSC Chemistry [43]. Due to the scarcity of redox potential measurements for solutes in flibe salt, the experimental molten salt redox potentials are taken from only one reference [61].

It should be noted that experimentally measured redox potentials needed some processing to be comparable to the FPMD results. Specifically, the experimental data [61] shown in Fig. 2 and Table 2 were originally measured from a $\mathrm{Ni}(\mathrm{II}) / \mathrm{Ni}(0)$ reference, which was measured in molten $\mathrm{LiF}-\mathrm{BeF}_{2}-\mathrm{ZrF}_{4}(65.6-29.4-5.0 \mathrm{~mol} \%)$ at $773 \mathrm{~K}$, and the values were converted to a $\mathrm{F}_{2} / \mathrm{F}^{-}$reference and the temperature effects were compensated theoretically. Therefore, in order to convert the data from Ref. [61] to our composition, temperature and the $\mathrm{F}_{2} / \mathrm{F}^{-}$reference it was necessary to 
make a few assumptions. The first assumption was that the effect of $5 \mathrm{~mol} \%$ of $\mathrm{ZrF}_{4}$ in standard redox potentials in flibe is negligible. The second assumption was that the emf (electromotive force) of $\mathrm{Ni}(\mathrm{II}) / \mathrm{Ni}(0)$ (vs. $\mathrm{F}_{2} / \mathrm{F}^{-}$) at $773 \mathrm{~K}$ is $-2.778 \mathrm{~V}$, which was calculated from the HSC Chemistry database [43] for the reduction reaction of $\mathrm{NiF}_{2}$ (i.e. $\mathrm{NiF}_{2}=\mathrm{Ni}+\mathrm{F}_{2}(\mathrm{~g})$ ). The last assumption was that the temperature effect on redox potentials can be estimated thermodynamically from the solid fluoride reactions, which assumption was needed to convert values from $773 \mathrm{~K}$ to $973 \mathrm{~K}$.

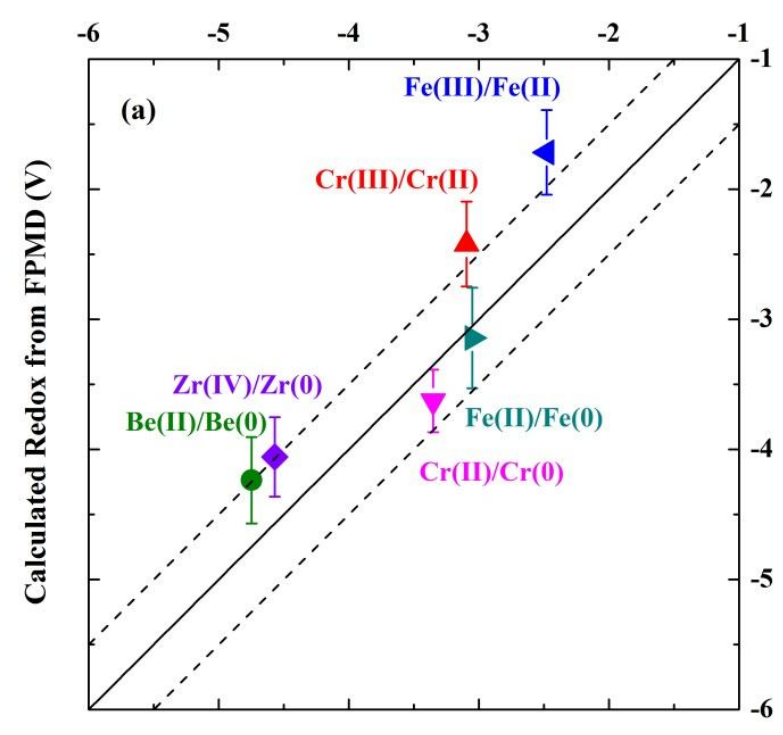

Experimental Redox Potential (V)

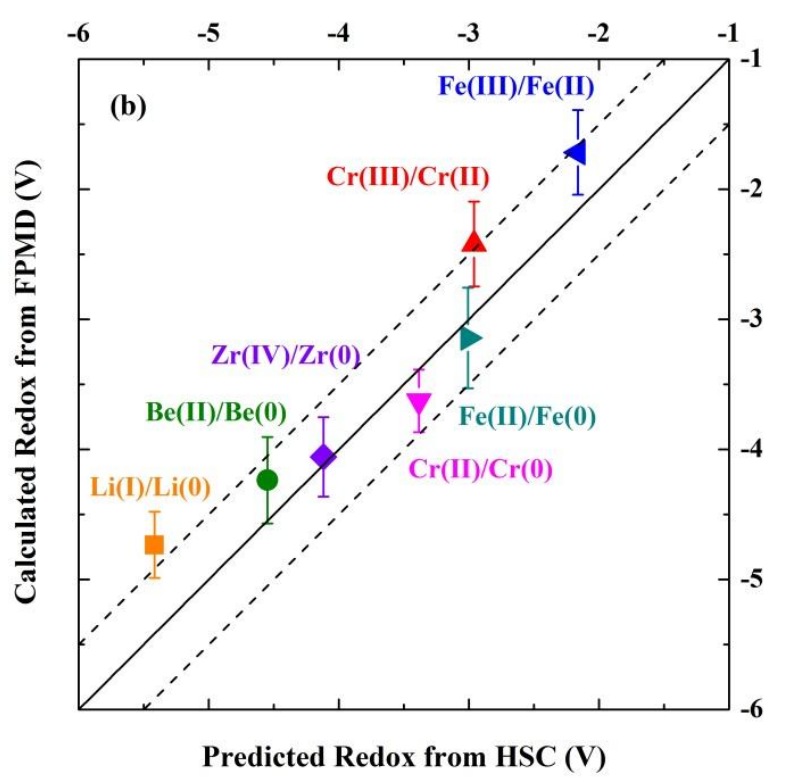

Predicted Redox from HSC (V)

Fig. 2. (a) Comparison of calculated redox potential of several redox couples in molten flibe salt at 973K by FPMD (y-axis) with the (a) experimental redox potential and the (b) predicted redox potential from the thermodynamic database for pure solid form of fluorides [43]. Dashed lines show $\pm 0.5 \mathrm{~V}$ range from the one-to-one correspondence line. The error bars represent twice the standard error of the mean.

Table 2. Calculated redox potential of several redox couples (vs. $F_{2} / F^{-}$reference) in molten flibe salt at $973 \mathrm{~K}$ with the predicted redox potential from the thermodynamic database [43].

\begin{tabular}{|c|c|c|c|c|c|c|}
\hline Redox couples & $\begin{array}{c}\text { Prediction } \\
\text { from HSC } \\
{[43]} \\
(\mathrm{V}) \\
\end{array}$ & $\begin{array}{l}\text { FPMD } \\
\text { (this } \\
\text { study) } \\
\text { (V) } \\
\end{array}$ & $\begin{array}{l}\text { FPMD } \\
2 \sigma \text { Std. } \\
\text { Error } \\
(\mathrm{V}) \\
\end{array}$ & $\begin{array}{l}\frac{C^{S}}{n \cdot e} \\
(\mathrm{~V})\end{array}$ & $\begin{array}{c}\text { Experimental } \\
\operatorname{Redox}^{\mathrm{a}}[61] \\
\text { (V) }\end{array}$ & References \\
\hline $\mathrm{Li}(\mathrm{I}) / \mathrm{Li}(0)$ & -5.417 & -4.734 & 0.254 & 0.260 & - & - \\
\hline $\mathrm{Be}(\mathrm{II}) / \mathrm{Be}(0)$ & -4.549 & -4.236 & 0.332 & 0.522 & -4.749 & \multirow{4}{*}[61]{} \\
\hline $\mathrm{Zr}(\mathrm{IV}) / \mathrm{Zr}(0)$ & -4.119 & -4.058 & 0.306 & 0.438 & -4.570 & \\
\hline $\mathrm{Fe}(\mathrm{III}) / \mathrm{Fe}(\mathrm{II})$ & -2.070 & -1.716 & 0.325 & 0.587 & -3.051 & \\
\hline $\mathrm{Fe}(\mathrm{II}) / \mathrm{Fe}(0)$ & -3.054 & -3.144 & 0.387 & 0.584 & -2.479 & \\
\hline
\end{tabular}




\begin{tabular}{|c|l|l|l|l|l|l|}
\hline $\mathrm{Cr}(\mathrm{III}) / \mathrm{Cr}(\mathrm{II})$ & -2.961 & -2.421 & 0.326 & 0.275 & -3.352 & \\
\hline $\mathrm{Cr}(\mathrm{II}) / \mathrm{Cr}(0)$ & -3.385 & -3.627 & 0.240 & 0.619 & -3.095 & \\
\hline
\end{tabular}

${ }^{\text {a }}$ Experimentally measured redox potentials were calculated from reference [61], which were measured in molten LiF-BeF $-\mathrm{ZrF}_{4}(65.6-29.4-5.0 \mathrm{~mol} \%)$ at $773 \mathrm{~K}$ using $\mathrm{Ni}(\mathrm{II}) / \mathrm{Ni}(0)$ reference, by converting the values for $\mathrm{F}_{2} / \mathrm{F}-$ reference and compensating temperature effect theoretically.

\subsection{Sources of error in the redox calculation}

Although calculated redox potentials for solutes are not perfectly matched with the measurements and the prediction, most of the calculated redox potentials are within the range of $\pm 0.5 \mathrm{~V}$ from the experimental data. The calculated values have significant uncertainty as shown by the two sigma (95.4\% confidence level) standard errors presented as y-axis error bars in Fig. 1 and Fig. 2. Given these error bars, it is possible that more converged calculations would be somewhat closer to experiments, but there are a number of points that are clearly not consistent with the experimental values even within a two sigma error bar. Various reasons can be proposed to explain the difference between the calculation and references (measurements or prediction), and we think the most dominant are likely to be DFT errors and the several approximations that we have made in the approach.

First, as can be seen in the previous modeling work of pure molten salts [17], proper selection of exchange-correlation (XC) functional is essential in the first-principles modeling of liquid system. The van der Waals dispersion interaction also plays an important role in the liquid system. Although we made an effort to choose the most appropriate XC functional and dispersion terms for the molten salt based on previous analysis [17], the equilibrium volume of molten salts were strongly influenced by the XC functional. This influence implies that the magnitude of the error on the equilibrium volume is large compared to that obtained in solid systems (typically $\pm 1 \%$ in terms of lattice constant [62]), which suggests that salt simulations may be less accurate that typical solid simulations. Like the volume, the energy will also be sensitive to the XC functional and may have inaccuracies in the salts, although the errors have not been evaluated in this study beyond the solute redox comparisons shown.

Second, several approximations were made in the redox calculations to keep the study practical. As discussed above (Section 2.3), we used energy from the FPMD simulations instead of enthalpy in the redox formulation (this is equivalent to assuming $\mathrm{P}=0$ ). However, in Section 2.2, we showed that the error on the estimated energy is about $20 \mathrm{meV}$, which is not significant on the scale of the errors we find in the redox predictions. It was also assumed that the entropy difference between solutes $(\mathrm{X})$ and chloride $\left(\mathrm{XCl}_{\mathrm{n}}\right)$ dissolved in $\mathrm{LiCl}-\mathrm{KCl}$ is the same as the difference of entropy between solid phase $\mathrm{X}$ and solid phase $\mathrm{XCl}_{\mathrm{n}}$. Likewise, the entropy difference between solutes $(\mathrm{Y})$ and fluoride $\left(\mathrm{YF}_{\mathrm{n}}\right)$ dissolved in flibe is assumed to be same with 
the difference of entropy between solid phase $\mathrm{Y}$ and solid phase $\mathrm{YF}_{\mathrm{n}}$. It is difficult to be sure the errors associated with this assumption, but these entropy corrections typically contribute about $0.26 \sim 0.62 \mathrm{~V}$ to the redox potential depending on the solute species, as shown in Table 1 and Table 2. The errors in our model are expected to only be a fraction of this scale, as we do include the solid phase entropy differences as an approximation to the liquid. However, it is possible that errors associated with our treatment the entropy changes in the chlorization (or fluorization) of solute in the molten salts could play a significant role in the overall redox potential. We note that the calculation of the free energy difference between two systems can be more rigorously obtained with thermodynamic integration along a connecting path in molecular dynamics simulation [63]. In particular, this approach has been used to obtain relative free energies of different dissolved cations in molten salts by Salanne, et al. [23]. However, thermodynamic integration tends to be very computationally expensive. For example, Salanne, et al. performed a total of 1.1 nanoseconds of simulation for each relative potential they determined. We therefore determined that such approaches were not practical for FPMD at the present time and pursued a more approximate approach in this work.

We note that for our two salt systems there are more predictions that are two sigma or more above the experimental values ( 6 cases) than two sigma below the experimental values ( 3 cases). However, given the relatively small sampling these results do not suggest a strong bias in any particular direction. We believe that further refinement is possible with exploration of additional first-principles exchange-correlation functionals as well as more extensive simulation employing larger simulation cells, longer simulations with more sampling of the simulation runs, running simulations at the most accurate equilibrium volume for solute systems, and improved modeling of the entropy.

It is of interest to summarize how closely the solid phase and molten salt redox energies agree when both are taken from experiments, as we use both for comparison to our simulations. Fig. 3 shows a comparison of experimental redox potentials in both molten salts together with the predicted solid phase redox potentials from HSC Chemistry. The predicted solid redox potentials also show differences with the experimental molten salt measurements up to $\sim 0.4 \mathrm{~V}$. Because the dissolved solute in molten salts does not behave as it does in solid phase, the experimental molten salt redox potentials do not need to match with the predicted solid redox potentials. However, as stated above, predicted solid phase redox values are generally quite close to the potentials measured in the salts, especially for the redox potentials in $\mathrm{LiCl}-\mathrm{KCl}$ salt. The root mean square (RMS) error for the predicted solid phase redox to the experimental redox measurements in $\mathrm{LiCl}-\mathrm{KCl}$ and flibe were about $0.23 \mathrm{~V}$ and $0.54 \mathrm{~V}$, respectively. It is possible that the multiple redox measurements available in $\mathrm{LiCl}-\mathrm{KCl}$ contribute to the lower RMS error. 


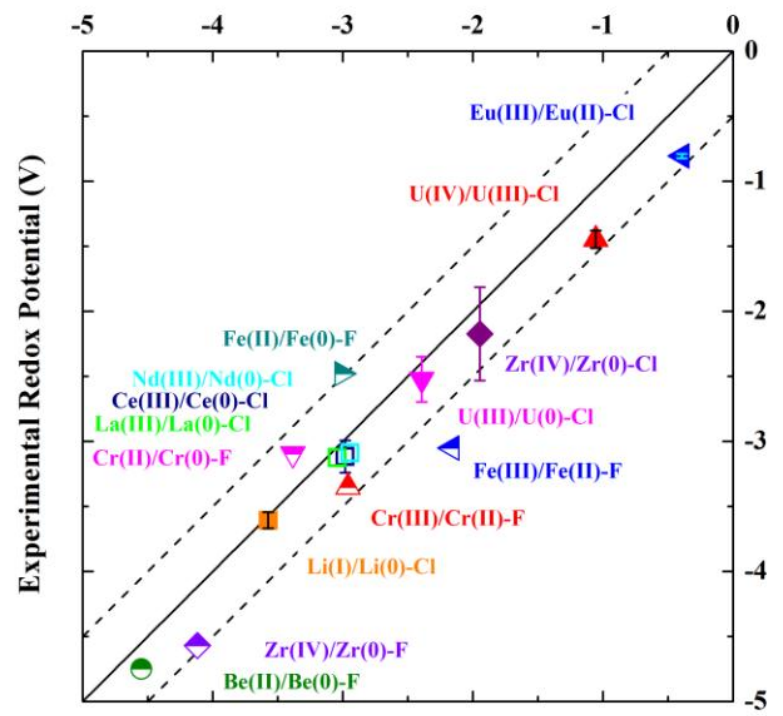

Predicted Redox from HSC (V)

Fig. 3. Comparison of experimental redox potentials in both molten salts with the predicted redox potentials from pure solid compounds.

\section{Behavior of solutes in molten salts}

\subsection{Local structure surrounding solutes}

Local structure of dissolved solutes can help understand the fundamental chemistry involved in the dissolution and has been studied in the $\mathrm{LiCl}-\mathrm{KCl}$ and flibe salts by analyzing the FPMD simulation trajectory. VMD [64] was used to visualize the trajectory of FPMD simulation. Fig. 4 shows snapshots of FPMD trajectory for several solutes in the flibe and LiCl-KCl salts. Fig. 4(a) and (b-c) are showing local structure of neutral $\mathrm{Zr}$ and $\mathrm{Zr}^{4+}$ in flibe, respectively. In flibe salt, pink, magenta, purples balls are $\mathrm{Li}, \mathrm{Be}$ and $\mathrm{F}$ ions, respectively. Solute $\mathrm{Zr}$ is gray.

In this study, behavior of neutral atom was also simulated. As a representative of general neutral solutes in molten salts, neutral $\mathrm{Zr}$ in flibe is shown in Fig. 4(a). In general, neutral atoms have weaker attraction and so form fewer anion neighbors compared to the ionized atoms (Fig. 4(b) and (c)). When the solute is dissolved in molten salts, its coordination with the surrounding anions fluctuates significantly during the simulation, as shown in Fig. 4(b) and (c).

Fig. 4(d) shows the snapshot of the FPMD simulation for the $\mathrm{Zr}^{4+}$ in $\mathrm{LiCl}-\mathrm{KCl}$. In LiCl-KCl, $\mathrm{Li}$ is also pink, and $\mathrm{K}$ and $\mathrm{Cl}$ ions are cyan and yellow, respectively. Comparing the Fig. 4(b) and Fig. 4(d), we can find that the solute behavior is different when it dissolved in different molten salts, although the simulation temperature is also different. Dissolved $\mathrm{Zr}^{4+}$ in $\mathrm{LiCl}-\mathrm{KCl}$, unlike 
the $\mathrm{Zr}^{4+}$ in flibe, has a quite stable local structure with surrounding anions and an octahedral-like $\mathrm{Cl}^{-}$cage is maintained during the simulation.

Fig. 4(e) shows the FPMD snapshot for $\mathrm{Sr}^{2+}$ in $\mathrm{LiCl}-\mathrm{KCl}$ and Fig. 4(f)-(h) show the snapshots for $\mathrm{U}^{3+}$ in LiCl-KCl. Generally, ions which oxidation state is $(2+)$ have fewer bonds with the surrounding anions than the ion (3+) or (4+) as shown in Fig. 4(e)-(h). This tendency is also observed in Fig. 5 and Table 3. Fig. 4(f)-(h) also show that certain ions can have various coordination polyhedral during the simulation.
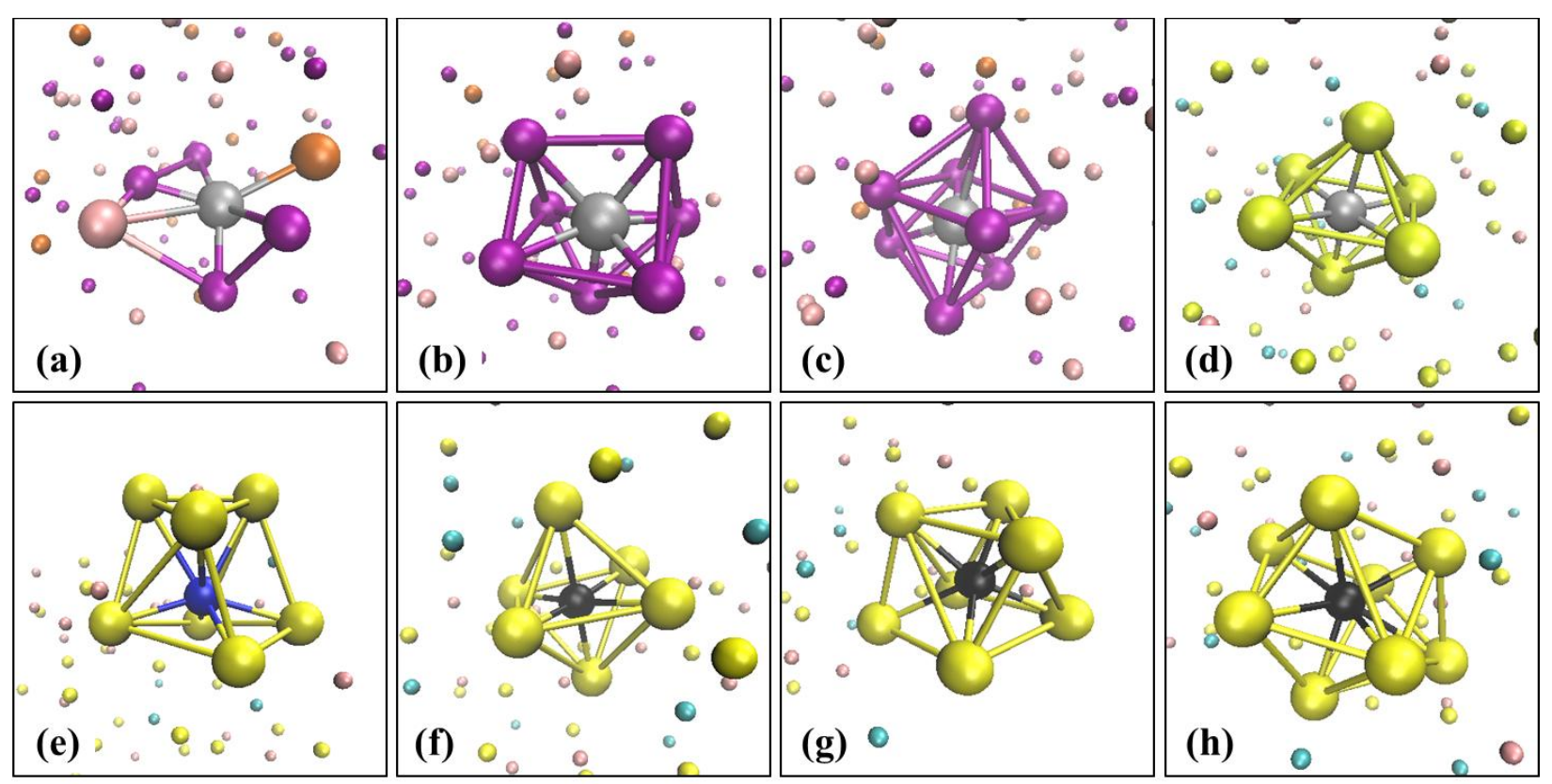

Fig. 4. Snapshots of the FPMD simulation trajectory showing the local structure of solute ion in molten salts, (a) neutral $\mathrm{Zr}$ in flibe; (b), (c) $\mathrm{Zr}^{4+}$ in flibe; (d) $\mathrm{Zr}^{4+}$ in $\mathrm{LiCl}-\mathrm{KCl}$; (e) $\mathrm{Sr}^{2+}$ in $\mathrm{LiCl}-\mathrm{KCl}$; (f), (g), (h) $\mathrm{U}^{3+}$ in LiCl-KCl. In flibe salt, pink, magenta, purples balls are $\mathrm{Li}$, Be and $\mathrm{F}$ ions, respectively. $\mathrm{In} \mathrm{LiCl}-\mathrm{KCl}, \mathrm{Li}$ is also pink, and $\mathrm{K}$ and $\mathrm{Cl}$ ions are cyan and yellow, respectively. Solute $\mathrm{Zr}$ in both salts is gray. Blue and black balls are solute $\mathrm{Sr}$ and $\mathrm{U}$ in LiCl-KCl, respectively.

To quantify the average local coordination of ionized solutes in molten salts, the radial distribution function (RDF) was analyzed and quantified as depicted in Section 2.4 (see Fig. 5 and Table 3). Fig. 5 shows the RDFs of various solutes in both $\mathrm{LiCl}-\mathrm{KCl}$ and flibe salt. Solid lines denote the RDFs between solute ion and surrounding anions, while dashed lines are neighbor function, $N(r)$, which is used to quantify the first-shell coordination number. 
Qualitatively, when a solute has higher oxidation states, it will make more bonds with anions and the first peak in the RDF is larger. The coordination number of the solute with surrounding anions can be estimated by integrating the radial distribution function (RDF) from zero to the first minimum. Calculated coordination numbers for each solute are summarized in Table 3 . We note that the RDF analysis results for the solute $\mathrm{Cr}$ in flibe was presented in a previous study [17]. Comparing the first-peak radii and coordination numbers for $\mathrm{Fe}^{0 / 2+/ 3+}-\mathrm{F}^{-}$with the values for $\mathrm{Cr}^{0 / 2+/ 3+}-\mathrm{F}^{-}$, it is seen that local structure of $\mathrm{Fe}$ ions in flibe is similar with $\mathrm{Cr}$ ions in flibe.
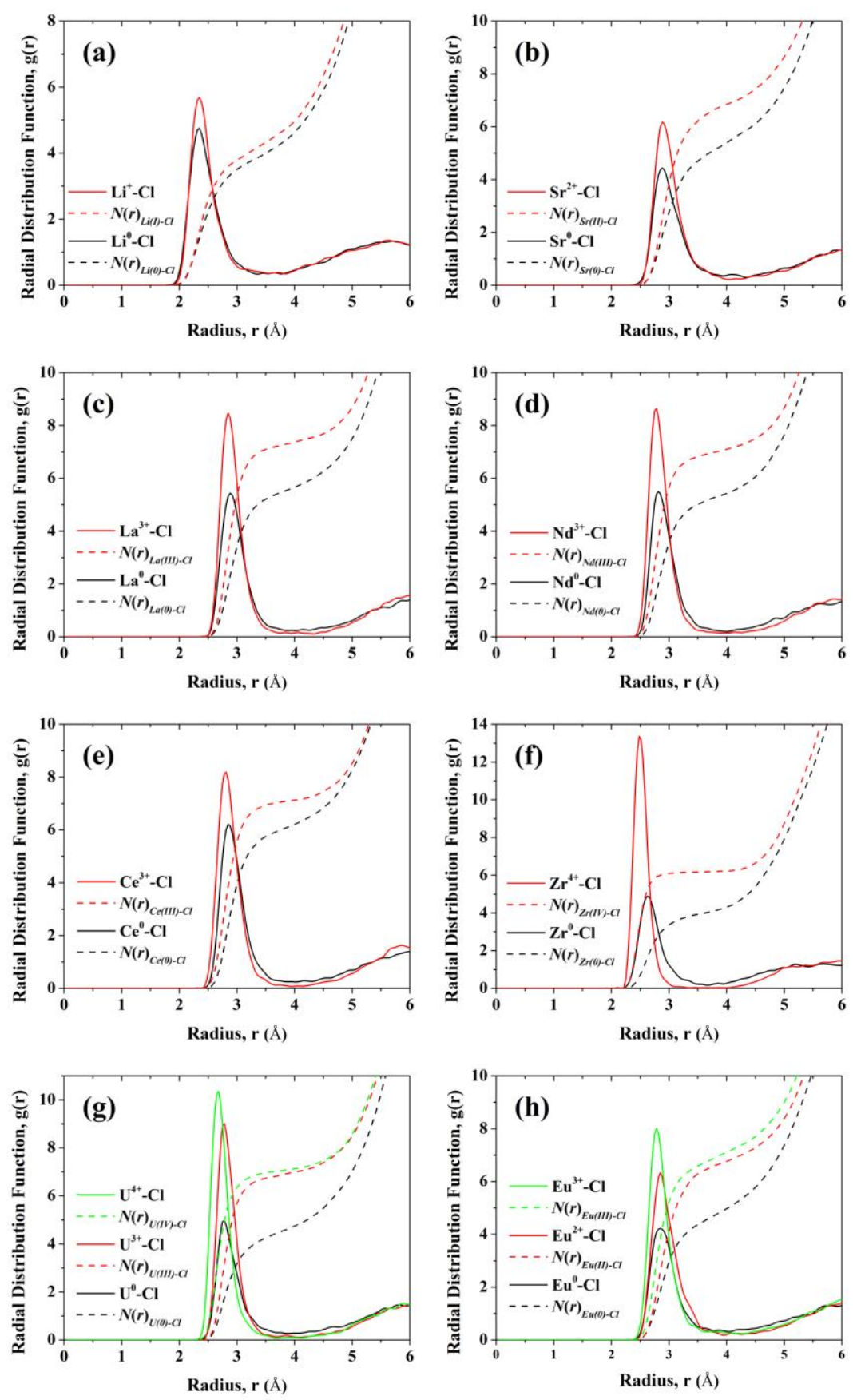

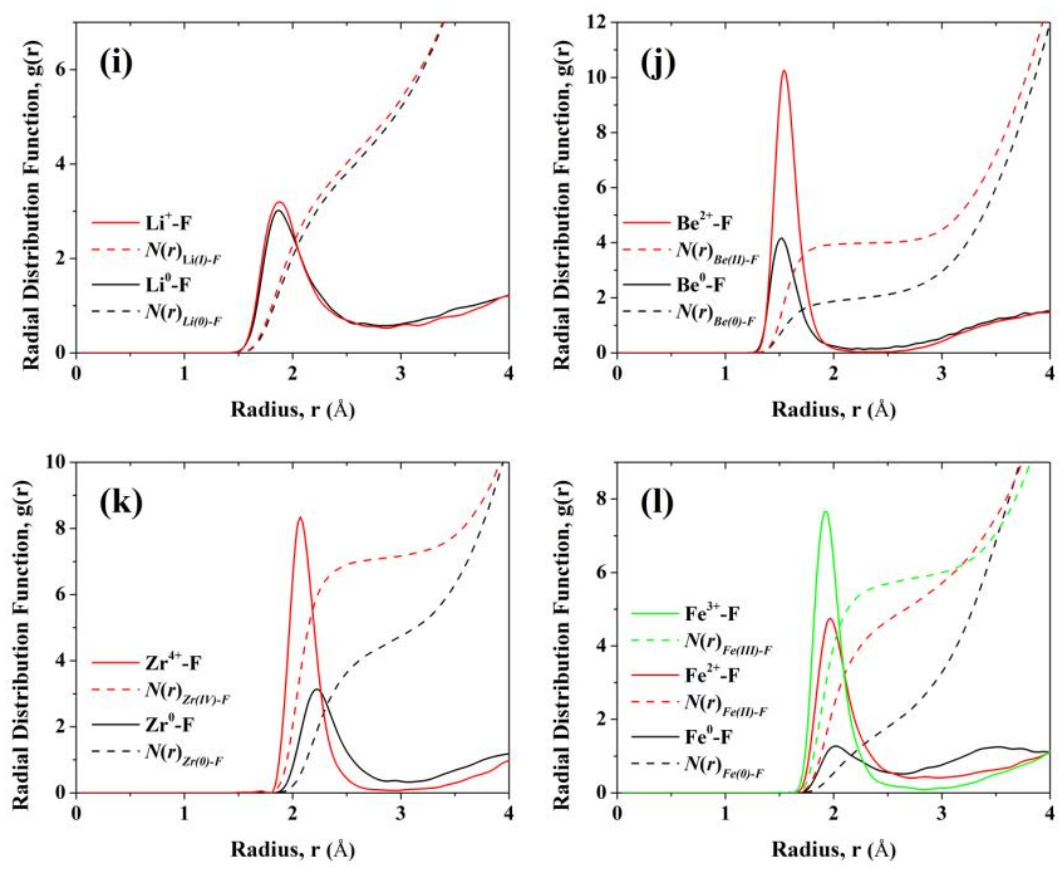

Fig. 5. Radial distribution functions (RDF) of solute (a) Li; (b) Sr; (c) La; (d) Nd; (e) Ce; (f) Zr; (g) $\mathrm{U}$; (h) Eu in $\mathrm{LiCl}-\mathrm{KCl}$ and (i) $\mathrm{Li}$; (j) $\mathrm{Be}$; (k) $\mathrm{Zr}$; (l) Fe in flibe. Solid lines denote the RDFs of neutral and ionized solutes, while dash lines are neighbor function, $N(r)$, between solute and anion.

As observed in trajectory snapshots (Fig. 4(b)-(d)), in case of the Zr, it exhibits more bonds with the F- ions than with the $\mathrm{Cl}$ - ions and hence larger coordination number (7.1 vs. 6.2). Zr shows various local structures having 6-8 bonds with surrounding F- ions, yielding an average coordination number of $\sim 7 \mathrm{~F}^{-}$in its first neighbor shell. This trend could be due to simple size effects and packing constraints, as the radius of $\mathrm{F}^{-}$is smaller than $\mathrm{Cl}^{-}$(approximately 1.29 $\mathrm{A}-1.33$ $\AA$ for $\mathrm{F}^{-}$vs. $1.81 \AA$ for $\mathrm{Cl}^{-}$based on Shannon ionic radii [65]). The estimated first-peak radius and coordination numbers are also compared with the most relevant available experimental measurements in Table 3. In many cases the experiments are at different temperatures, and when it is the case the experimental temperatures are given in parentheses. Also, in most cases, the solute-solvent system is not the same with the simulation, for example, the coordination of $\mathrm{U}^{4+}$ with $\mathrm{Cl}^{-}$ions were measured as a function of the chloride concentration in aqueous solution [66]. It also should be noted that the local structure can be greatly affected by the concentration of solute chlorides (or fluorides) in the solution. In molten $\mathrm{LiF}-\mathrm{ZrF}_{4}$ system, it was found that the coordination number between $\mathrm{Zr}^{4+}$ and $\mathrm{F}^{-}$decreases about $10 \%$ from the initial local concentration values as the concentration increases up to $35 \mathrm{~mol} \%$ of $\mathrm{ZrF}_{4}$ [67]. Finally, we note that various techniques such as neutron diffraction (ND), x-ray diffraction (XRD), nuclear magnetic resonance (NMR), and extended x-ray absorption fine structure (EXAFS) were used from different literature to obtain the experimental data. Therefore, the comparison with experimental coordination values should be considered for qualitative validation only. 
Nonetheless, given these issues, the measured data are in qualitatively good agreement with the estimated values from FPMD. However, because the lifetimes of the solute-anion compound is not stable and its lifetimes can strongly vary, the coordination number is just one indicator of bond strength and other measures are needed to provide a more complex picture of local structure and bonding strengths.

Table 3. First-peak radius and first-shell coordination numbers for solute ions and anion $\left(\mathrm{Cl}^{-}\right.$or $\left.\mathrm{F}^{-}\right)$ pairs in $\mathrm{LiCl}-\mathrm{KCl}(773 \mathrm{~K})$ and flibe (973K) in comparison with the experiments. First shell coordination numbers are determined by the integral of the RDF up to its first minimum. Coordination number standard errors are estimated as 0.2 for the solute ions (see Sec. 2.2).

\begin{tabular}{|c|c|c|c|c|c|c|c|}
\hline \multirow[t]{2}{*}{ Salt } & \multirow[t]{2}{*}{ Ion pair } & \multirow[t]{2}{*}{$\begin{array}{l}\text { First-peak } \\
\text { height ( }) \text { ) }\end{array}$} & \multicolumn{2}{|c|}{$\begin{array}{l}\text { First-peak } \\
\text { radius }(\AA)\end{array}$} & \multicolumn{2}{|c|}{ Coordination number } & \multirow[t]{2}{*}{$\begin{array}{l}\text { Referen } \\
\text { ces }\end{array}$} \\
\hline & & & FPMD & Experimental & FPMD & Experimental & \\
\hline \multirow{18}{*}{$\begin{array}{l}\mathrm{LiCl}- \\
\mathrm{KCl}\end{array}$} & $\mathrm{Li}^{0}-\mathrm{Cl}^{-}$ & 4.7 & 2.35 & - & 4.0 & - & - \\
\hline & $\mathrm{Li}^{+}-\mathrm{Cl}^{-}$ & 5.7 & 2.35 & 2.21 & 4.4 & 4.1 & [68] \\
\hline & $\mathrm{Sr}^{0}-\mathrm{Cl}^{-}$ & 4.4 & 2.88 & - & 5.6 & - & - \\
\hline & $\mathrm{Sr}^{2+}-\mathrm{Cl}^{-}$ & 6.2 & 2.89 & $2.90(1198 \mathrm{~K})$ & 7.0 & $6.9(1198 \mathrm{~K})$ & [69] \\
\hline & $\mathrm{La}^{0}-\mathrm{Cl}^{-}$ & 5.4 & 2.89 & - & 5.7 & - & - \\
\hline & $\mathrm{La}^{3+}-\mathrm{Cl}^{-}$ & 8.5 & 2.85 & $2.85(1150 \mathrm{~K})$ & 7.4 & $7.1(1150 \mathrm{~K})$ & [70] \\
\hline & $\mathrm{Nd}^{0}-\mathrm{Cl}^{-}$ & 5.5 & 2.82 & - & 5.4 & - & - \\
\hline & $\mathrm{Nd}^{3+}-\mathrm{Cl}^{-}$ & 8.7 & 2.77 & $2.73(1123 \mathrm{~K})$ & 7.1 & $6.96(1123 \mathrm{~K})$ & [71] \\
\hline & $\mathrm{Ce}^{0}-\mathrm{Cl}^{-}$ & 6.2 & 2.86 & - & 6.2 & - & - \\
\hline & $\mathrm{Ce}^{3+}-\mathrm{Cl}^{-}$ & 8.1 & 2.80 & $2.81(1173 \mathrm{~K})$ & 7.1 & $6.52(1173 \mathrm{~K})$ & [71] \\
\hline & $\mathrm{Zr}^{0}-\mathrm{Cl}^{-}$ & 4.9 & 2.64 & - & 4.0 & - & - \\
\hline & $\mathrm{Zr}^{4+}-\mathrm{Cl}^{-}$ & 13.1 & 2.49 & $2.51(723 \mathrm{~K})$ & 6.2 & $5.9(723 \mathrm{~K})$ & [72] \\
\hline & $\mathrm{U}^{0}-\mathrm{Cl}^{-}$ & 5.0 & 2.77 & - & 4.6 & - & - \\
\hline & $\mathrm{U}^{3+}-\mathrm{Cl}^{-}$ & 9.0 & 2.77 & $\begin{array}{l}2.84(1200 \mathrm{~K}) \\
2.85(1200 \mathrm{~K})\end{array}$ & 7.0 & $\begin{array}{l}6(1200 \mathrm{~K}) \\
8(1200 \mathrm{~K})\end{array}$ & $\begin{array}{l}{[73]} \\
{[74]}\end{array}$ \\
\hline & $\mathrm{U}^{4+}-\mathrm{Cl}^{-}$ & 10.4 & 2.67 & $2.71(573 \mathrm{~K})$ & 7.1 & $7.7(573 \mathrm{~K})$ & {$[66]$} \\
\hline & $\mathrm{Eu}^{0}-\mathrm{Cl}^{-}$ & 4.2 & 2.86 & - & 5.0 & - & - \\
\hline & $\mathrm{Eu}^{2+}-\mathrm{Cl}^{-}$ & 6.3 & 2.85 & - & 6.8 & - & - \\
\hline & $\mathrm{Eu}^{3+}-\mathrm{Cl}^{-}$ & 7.9 & 2.78 & - & 7.2 & - & - \\
\hline \multirow{12}{*}{ Flibe } & $\mathrm{Li}^{0}-\mathrm{F}^{-}$ & 3.0 & 1.87 & - & 4.7 & - & - \\
\hline & $\mathrm{Li}^{+}-\mathrm{F}^{-}$ & 3.2 & 1.87 & $1.85(1023 \mathrm{~K})$ & 5.2 & $4(1023 K)$ & [75] \\
\hline & $\mathrm{Be}^{0}-\mathrm{F}^{-}$ & 4.0 & 1.53 & - & 2.0 & - & - \\
\hline & $\mathrm{Be}^{2+}-\mathrm{F}^{-}$ & 10.3 & 1.55 & $1.58(1023 \mathrm{~K})$ & 4.0 & $4.0(1023 \mathrm{~K})$ & [75] \\
\hline & $\mathrm{Zr}^{0}-\mathrm{F}^{-}$ & 3.1 & 2.23 & - & 4.8 & - & - \\
\hline & $\mathrm{Zr}^{4+}-\mathrm{F}^{-}$ & 8.3 & 2.07 & $2.06(1120 \mathrm{~K})$ & 7.1 & $7.0(1120 \mathrm{~K})$ & {$[67]$} \\
\hline & $\mathrm{Fe}^{0}-\mathrm{F}^{-}$ & 1.3 & 2.05 & - & 2.1 & - & - \\
\hline & $\mathrm{Fe}^{2+}-\mathrm{F}^{-}$ & 4.8 & 1.97 & - & 5.2 & - & - \\
\hline & $\mathrm{Fe}^{3+}-\mathrm{F}^{-}$ & 7.6 & 1.94 & - & 5.9 & - & - \\
\hline & $\mathrm{Cr}^{0}-\mathrm{F}^{-}$ & 1.2 & 2.05 & - & 2.1 & - & - \\
\hline & $\mathrm{Cr}^{2+}-\mathrm{F}^{-}$ & 5.5 & 1.97 & - & 5.2 & - & - \\
\hline & $\mathrm{Cr}^{3+}-\mathrm{F}^{-}$ & 9.0 & 1.93 & - & 5.9 & - & - \\
\hline
\end{tabular}




\subsection{Self-diffusion of solutes in molten salt}

Self-diffusion coefficients of solutes ( $\mathrm{Li}, \mathrm{Sr}, \mathrm{La}, \mathrm{Nd}, \mathrm{Ce}, \mathrm{Zr}, \mathrm{U}$ and $\mathrm{Eu}$ ) in $\mathrm{LiCl}-\mathrm{KCl}$ at $773 \mathrm{~K}$ and solutes ( $\mathrm{Li}, \mathrm{Be}, \mathrm{Zr}, \mathrm{Fe}$ and $\mathrm{Cr}$ ) in flibe at $973 \mathrm{~K}$ were analyzed and compiled together. To obtain reliable statistical averages of the self-diffusion coefficient of the solute ion in the salt, nine independent FPMD simulations for 4ps (4000 time steps) were performed for each solute system as describe in Section 2.2. Then, the slopes of nine independent MSDs for each ion were averaged to determine the diffusion coefficient of solute ion. The error in the solute diffusivity was obtained by evaluating the standard error of the mean from these nine independent simulations.

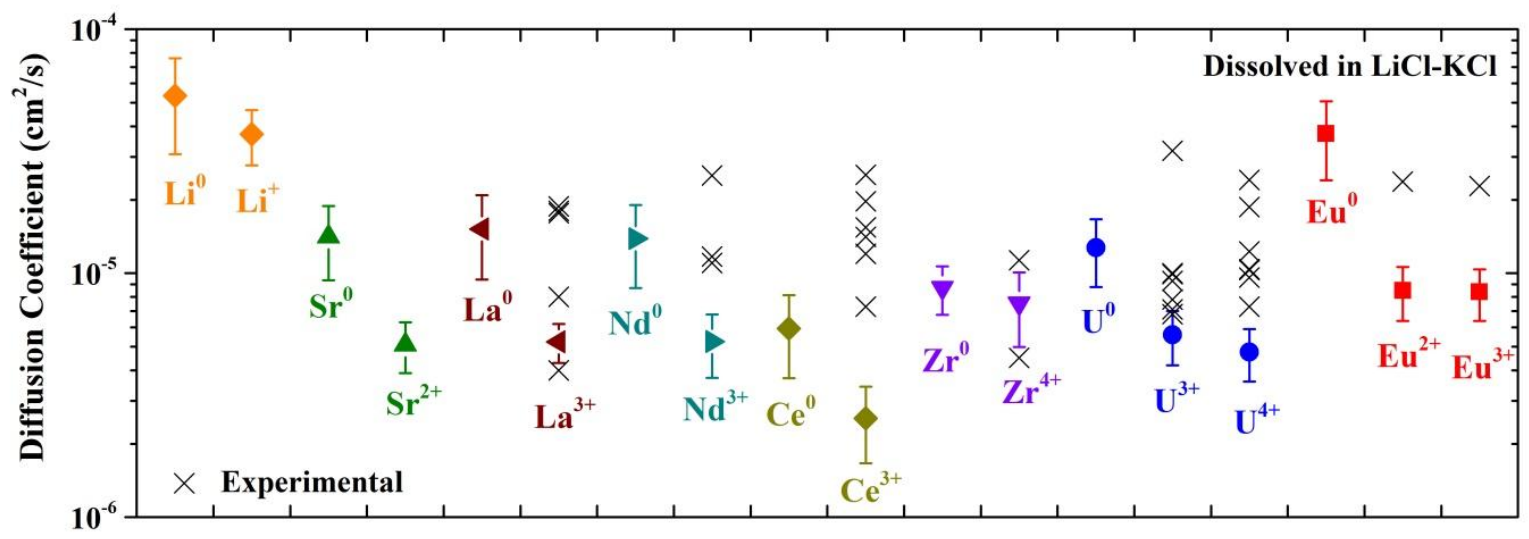

Fig. 6. Calculated diffusion coefficients of various solutes in $\mathrm{LiCl}-\mathrm{KCl}$ at 773K from FPMD simulations. Experimental diffusion coefficients (cross marks) are also shown for comparison. Error bars represent one sigma standard error of the mean from nine simulations.

Fig. 6 shows the calculated diffusion coefficients of various solutes in $\mathrm{LiCl}-\mathrm{KCl}$ at $773 \mathrm{~K}$ from FPMD simulations. As shown in the figure, FPMD is sensitive to the role of charge state of solute ions in molten salts. The neutral atom moves faster than the charged solute ion, presumably because the latter interact more with the surrounding anions. Fig. 6 also includes experimentally measured diffusion coefficients of which we are aware for comparison (see Table 4). The FPMD values are in most cases below the experimental values or in the lowest range of the spread of experimental values. This suggests that there may be some systematic error in the simulations yielding somewhat low diffusion coefficients. Discrepancies suggest that the FPMD predicted values are approximately 1-10 times low. 
Table 4. Calculated diffusion coefficients of solutes in LiCl-KCl at 773K from FPMD simulations. Error ranges represent one sigma standard error of the mean from nine simulations.

\begin{tabular}{|c|c|c|c|}
\hline Salt & Ions & $\begin{array}{l}\text { Self-diffusion coefficient } \\
\left(\mathrm{cm}^{2} / \mathrm{s} \times 10^{-5}\right)\end{array}$ & $\begin{array}{l}\text { Experimental } \\
\left(\mathrm{cm}^{2} / \mathrm{s} \times 10^{-5}\right)\end{array}$ \\
\hline \multirow{18}{*}{$\begin{aligned} \mathrm{LiCl}- \\
\mathrm{KCl}\end{aligned}$} & $\mathrm{Li}^{0}$ & $5.35 \pm 2.27$ & - \\
\hline & $\mathrm{Li}^{+}$ & $3.72 \pm 0.95$ & - \\
\hline & $\mathrm{Sr}^{0}$ & $1.41 \pm 0.48$ & - \\
\hline & $\mathrm{Sr}^{2+}$ & $0.51 \pm 0.12$ & - \\
\hline & $\mathrm{La}^{0}$ & $1.52 \pm 0.57$ & - \\
\hline & $\mathrm{La}^{3+}$ & $0.52 \pm 0.10$ & $\begin{array}{l}0.80^{\mathrm{a}}[56], 1.76^{\mathrm{b}}[55], 1.80[76], 1.87[77], 0.40- \\
1.88[3]\end{array}$ \\
\hline & $\mathrm{Nd}^{0}$ & $1.39 \pm 0.52$ & - \\
\hline & $\mathrm{Nd}^{3+}$ & $0.53 \pm 0.15$ & $1.10^{\mathrm{a}}[56], 1.17-2.51[3]$ \\
\hline & $\mathrm{Ce}^{0}$ & $0.59 \pm 0.22$ & - \\
\hline & $\mathrm{Ce}^{3+}$ & $0.25 \pm 0.09$ & $\begin{array}{l}1.2[76], 1.41[78], 1.54^{\mathrm{b}}[55], 1.97[77], 0.73- \\
2.53^{\mathrm{c}}[3]\end{array}$ \\
\hline & $\mathrm{Zr}^{0}$ & $0.87 \pm 0.20$ & - \\
\hline & $\mathrm{Zr}^{4+}$ & $0.75 \pm 0.25$ & $1.13[77], 0.011-0.45^{\mathrm{c}, \mathrm{d}}[79], 0.024-14.8^{\mathrm{c}, \mathrm{d}}[58]$ \\
\hline & $\mathrm{U}^{0}$ & $1.27 \pm 0.39$ & - \\
\hline & $\mathrm{U}^{3+}$ & $0.56 \pm 0.14$ & $\begin{array}{l}0.68 \text { [76], } 0.71[80], 0.78[3], 0.93 \text { [81], } 0.99 \text { [82], } \\
1.00[83], 3.17 \text { [52] }\end{array}$ \\
\hline & $\mathrm{U}^{4+}$ & $0.48 \pm 0.12$ & $\begin{array}{l}0.73[84], 0.96[81], 1.03[80], 1.04[82], 1.23 \text { [82], } \\
1.87[76], 2.41[52]\end{array}$ \\
\hline & $\mathrm{Eu}^{0}$ & $3.73 \pm 1.33$ & - \\
\hline & $\mathrm{Eu}^{2+}$ & $0.85 \pm 0.21$ & $2.37[77]$ \\
\hline & $\mathrm{Eu}^{3+}$ & $0.84 \pm 0.20$ & $2.28[60]$ \\
\hline
\end{tabular}

${ }^{\text {a }}$ Diffusion coefficients were measured at $723 \mathrm{~K}$.

${ }^{\mathrm{b}}$ Diffusion coefficients were measured at $750 \mathrm{~K}$.

${ }^{c}$ When range of diffusion coefficients were given, only highest and lowest values are shown in the plot.

${ }^{\mathrm{d}}$ Because the $\mathrm{Zr}$ diffusivity shows large scatter, only some of data is shown in the plot. 


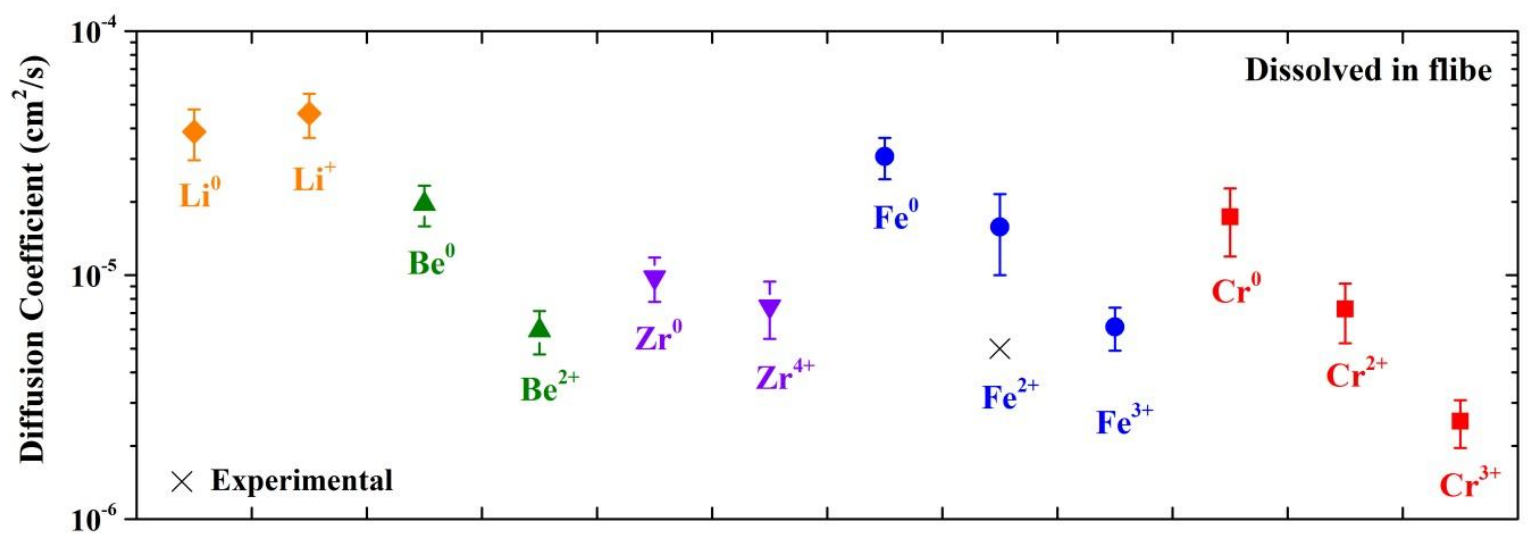

Fig. 7. Calculated diffusion coefficients of various solutes in flibe at 973K. Experimental diffusion coefficients (cross marks) are also shown for comparison. Error bars represent one sigma standard error of the mean from nine simulations.

Fig. 7 shows the self-diffusion coefficients of solutes in molten flibe at 973K. As in Fig. 6, Fig. 7 also shows that the neutral atom moves faster than the charged solute ion except the $\mathrm{Li}$, indicating that the FPMD is sensitive to the role of charge state of solute ions in molten salts. As observed in the structural analysis in Table 3, local structure for the $\mathrm{Li}^{0}$ and $\mathrm{Li}^{+}$were similar and this may explain the indistinguishable diffusion coefficients within their standard error of the mean. In flibe both the $\mathrm{Fe}^{3+}$ and $\mathrm{Cr}^{3+}$ show smaller diffusion coefficient than the $\mathrm{Fe}^{2+}$ and $\mathrm{Cr}^{2+}$, respectively, as expected from their stronger interaction with the anions (as evidenced by their larger coordination numbers).

We are aware of only one experiment of diffusion of the simulated elements in flibe. Specifically, the self-diffusion coefficient of $\mathrm{Fe}^{2+}\left(5 \times 10^{-6} \mathrm{~cm}^{2} / \mathrm{s}\right)$ in flibe at $773 \mathrm{~K}$ was measured and provided in the reference [76]. Although it is hard to compare this measurement directly with the calculated diffusivity of $\mathrm{Fe}^{2+}\left(1.6 \times 10^{-5}\right)$ in flibe at $973 \mathrm{~K}$ from FPMD, the effect of the temperature on the diffusion can be confirmed by comparing the values. If we assume that both measured and calculated $\mathrm{Fe}^{2+}$ diffusivities are accurate and that the temperature dependence of the diffusion in Arrhenius, the activation energy of $\mathrm{Fe}^{2+}$ ion in flibe is about $36.4 \times 10^{3} \mathrm{~J} / \mathrm{mol}-\mathrm{K}$. This value is comparable with the activation energies for the diffusion of $\mathrm{Li}, \mathrm{Be}$ and $\mathrm{F}$ ion in pure flibe (31.9, 43.3 and 34.1 J/mol-K, respectively), which were calculated in a previous study [17].

Table 5. Calculated diffusion coefficients of solutes in flibe at 973K from FPMD simulations. Error ranges represent one sigma standard error of the mean from nine simulations.

\begin{tabular}{|c|c|c|c|}
\hline Salt & Ions & $\begin{array}{c}\text { Self-diffusion coefficient } \\
\left(\mathrm{cm}^{2} / \mathrm{s} \times 10^{-5}\right)\end{array}$ & $\begin{array}{c}\text { Experimental } \\
\left(\mathrm{cm}^{2} / \mathrm{s} \times 10^{-5}\right)\end{array}$ \\
\hline
\end{tabular}




\begin{tabular}{|c|c|c|c|}
\hline \multirow{4}{*}{} & $\mathrm{Li}^{0}$ & $3.87 \pm 0.91$ & - \\
\cline { 2 - 4 } & $\mathrm{Li}^{+}$ & $4.60 \pm 0.94$ & - \\
\cline { 2 - 4 } & $\mathrm{Be}^{0}$ & $1.96 \pm 0.37$ & - \\
\cline { 2 - 4 } & $\mathrm{Be}^{2+}$ & $0.59 \pm 0.12$ & - \\
\cline { 2 - 4 } & $\mathrm{Zr}^{0}$ & $0.98 \pm 0.20$ & - \\
\cline { 2 - 4 } & $\mathrm{Zr}^{4+}$ & $0.75 \pm 0.20$ & - \\
\cline { 2 - 4 } & $\mathrm{Fe}^{0}$ & $3.07 \pm 0.59$ & $0.50^{\mathrm{a}}[76]$ \\
\cline { 2 - 4 } & $\mathrm{Fe}^{2+}$ & $1.58 \pm 0.58$ & - \\
\cline { 2 - 4 } & $\mathrm{Fe}^{3+}$ & $0.61 \pm 0.12$ & - \\
\cline { 2 - 4 } & $\mathrm{Cr}^{0}$ & $1.73 \pm 0.54$ & - \\
\cline { 2 - 4 } & $\mathrm{Cr}^{2+}$ & $0.73 \pm 0.20$ & - \\
\cline { 2 - 4 } & $\mathrm{Cr}^{3+}$ & $0.25 \pm 0.06$ & \\
\hline
\end{tabular}

${ }^{\mathrm{a}}$ Diffusion coefficients were measured at $773 \mathrm{~K}$.

As shown in the Fig. 6 and Fig. 7, the calculated diffusion coefficients are qualitatively in good agreement with the experimental measurements to the extent that comparisons are possible. However, as mentioned above, FPMD predicts smaller diffusivities compared to the mean of the experiments for $\mathrm{LiCl}-\mathrm{KCl}$. This underestimation of solute diffusivity can potentially be explained by the effect of solute concentration. Due to the small cells we are using, our solute chlorides (or fluorides) concentrations are generally high compared to experiments, which typically use $10^{2}$ $10^{5} \mathrm{ppm}$. Martin and Sridharan et al. [3] observed that the diffusion coefficient drops off significantly with lanthanide chloride concentration (see Fig. 8). The concentration of $\mathrm{LaCl}_{3}$ in our simulation cell with 64 atoms of $\mathrm{LiCl}-\mathrm{KCl}$ is about $1.2 \times 10^{5} \mathrm{ppm}$ and our data are in good agreement with the experimental diffusivity data measured at higher concentration of lanthanide, as shown in Fig. 8. However, our simulations seem to show little or no increase in D with lower concentration, although agreement at lower concentrations of La is less clear due to large uncertainties in the simulations. The concentration dependence of the diffusivity is an area that needs further study. 


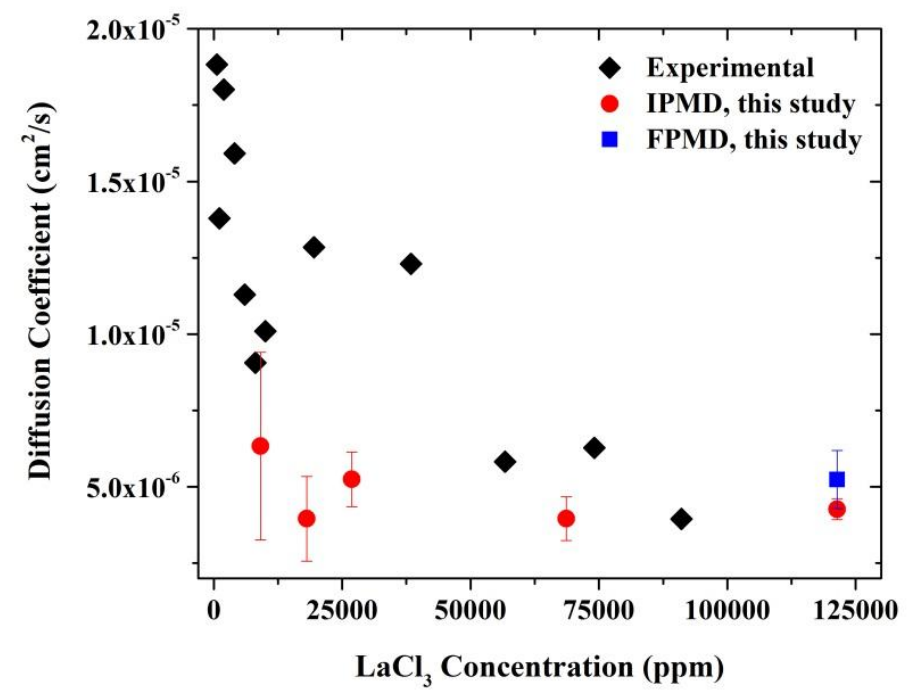

Fig. 8. Comparisons of calculated self-diffusion coefficients of $\mathrm{La}^{3+}$ in $\mathrm{LiCl}-\mathrm{KCl}$ at $773 \mathrm{~K}$ as a function of solute concentration from the IPMD (red circles) and the FPMD (blue square) with the experimental measurements (black diamond) [3].

\section{Conclusions}

First-principles molecular dynamics (FPMD) modeling was employed to study the solute behavior in molten $\mathrm{LiCl}-\mathrm{KCl}$ and flibe salts. We employed several strategies and assumptions to predict the solute properties accurately with a reasonable amount of computational cost.

A formulation for predicting standard redox potentials for solute species in molten salts was developed and used to predict a number of redox values for $\mathrm{LiCl}-\mathrm{KCl}$ and flibe. Agreement with experimental data was generally within $0.5 \mathrm{~V}$ and the source of error is likely a compound effect of uncertainty in the experiments, having to process the experimental data for comparison, DFT inaccuracies, and simulation limitations.

The structural analysis showed that local structure depends both on salts and solutes. The average coordination was calculated and found to agree well with experiments to the extent that comparisons were possible. The self-diffusion coefficients for solutes were calculated and those are also in reasonable agreement with the experiments, although calculation typically predicts a smaller diffusivity on the scale of 1-10x, depending on the solute. We suggest that this discrepancy may be due to concentration effects associated with the relatively high concentrations used in this study compared to typical experiments.

This study demonstrates that FPMD can be used to model the solute behavior in molten salts. FPMD can be a powerful tool to study the solutes in molten systems because it includes the full 
electronic structure of the solutes and does not need empirical potentials to be developed to study new systems.

\section{Acknowledgements}

This research was primarily performed using funding received from the DOE Office of Nuclear Energy's Nuclear Energy University Programs (NEUP 10-100 for fluoride salts \& NEUP 10-418 for $\mathrm{LiCl}-\mathrm{KCl}$ salt). Additional support for the final stages of writing and editing the manuscript were provided by the National Science Foundation under Grant No. 110564. The authors acknowledge the Extreme Science and Engineering Discovery Environment (XSEDE), which is supported by National Science Foundation grant number OCI-1053575, and the Idaho National Laboratory's (INL) Center for Advance Modeling and Simulation (CAMS) for providing HPC resources that have contributed to the research results reported within this paper. 


\section{References}

[1] Pyrochemical Separations in Nuclear Applications: A Status Report. OECD Nuclear Energy Agency: 2004.

[2] H. Lee; G.I. Park; J.W. Lee; K.H. Kang; J.M. Hur, et al., Sci. Technol. Nucl. Install. 2013, 343492.

[3] S. Martin; K. Sridharan; T. Allen; M. Mohammadian; J. Sager, et al. In Physical and Electrochemical Properties of Molten LiCl-KCl Salt for Used Fuel Reprocessing, International Pyroprocessing Research Conference, Fontana, WI, Fontana, WI, 2012.

[4] K. Coscia; S. Nelle; T. Elliott; S. Mohapatra; A. Oztekin, et al., Journal of Solar Energy Engineering 2013, 135 (3), 034506-034506.

[5] H.L. Zhang; J. Baeyens; J. Degrève; G. Cacères, Renewable and Sustainable Energy Reviews 2013, 22 (0), 466-481.

[6] A Technology Roadmap for the Generation IV Nuclear Energy Systems, GIF-002-00. U.S. DOE Nuclear Energy Research Advisory Committee and the Generation IV International Forum: 2002.

[7] C.W. Forsberg, Nuclear Technology 2003, 144 (3), 289-302.

[8] S. Greene In Fluoride Salt-cooled High Temperature Reactors - Technology Status and Development Strategy, ICENES-2011, San Francisco, CA, San Francisco, CA, 2011.

[9] K.-p. Chen; X.-w. Zhang, Ceramics International 2010, 36 (5), 1523-1527.

[10] T. Kimura, Molten Salt Synthesis of Ceramic Powders. 2011.

[11] M.V. Reddy; Z. Beichen; K.P. Loh; B.V.R. Chowdari, CrystEngComm 2013, 15 (18), 3568-3574.

[12] F. Lantelme; H. Groult, Molten Salts Chemistry: From Lab to Applications. Elsevier Science: 2013.

[13] M. Kondo; T. Nagasaka; A. Sagara; N. Noda; T. Muroga, et al., Journal of Nuclear Materials 2009, 386-88, 685-688.

[14] G. Zheng; B. Kelleher; G. Cao; K. Sridharan; M. Anderson, et al., Investigation of 2LiF-BeF2 (FLiBe): Salt Transfer, Corrosion Tests and Characterization. In American Nuclear Society Winter Meeting, Washington, DC, 2013; Vol. 108.

[15] D. Olander, Journal of Nuclear Materials 2002, 300 (2-3), 270-272.

[16] A. Bengtson; H.O. Nam; S. Saha; R. Sakidja; D. Morgan, Computational Materials Science 2014, 83 (0), 362-370.

[17] H.O. Nam; A. Bengtson; K. Vörtler; S. Saha; R. Sakidja, et al., Journal of Nuclear Materials 2014, 449 (1-3), 148-157. 
[18] L. Martínez; R. Andrade; E.G. Birgin; J.M. Martínez, Journal of Computational Chemistry 2009, 30 (13), 2157-2164.

[19] S. Plimpton, Journal of Computational Physics 1995, 117 (1), 1-19.

[20] M.L. Huggins; J.E. Mayer, The Journal of Chemical Physics 1933, 1 (9), 643-646.

[21] F.G. Fumi; M.P. Tosi, Journal of Physics and Chemistry of Solids 1964, 25 (1), 31-43.

[22] M.P. Tosi; F.G. Fumi, Journal of Physics and Chemistry of Solids 1964, 25 (1), 45-52.

[23] M. Salanne; C. Simon; P. Turq; P.A. Madden, The Journal of Physical Chemistry B 2008, 112 (4), 1177-1183.

[24] R.J. Heaton; R. Brookes; P.A. Madden; M. Salanne; C. Simon, et al., The Journal of Physical Chemistry B 2006, 110 (23), 11454-11460.

[25] B. Larsen; T. Førland; K. Singer, Molecular Physics 1973, 26 (6), 1521-1532.

[26] G. Kresse; J. Hafner, Physical Review B 1993, 47 (1), 558-561.

[27] G. Kresse; J. Furthmüller, Physical Review B 1996, 54 (16), 11169-11186.

[28] G. Kresse; D. Joubert, Physical Review B 1999, 59 (3), 1758-1775.

[29] J.P. Perdew; K. Burke; M. Ernzerhof, Physical Review Letters 1996, 77 (18), 3865-3868.

[30] J.P. Perdew; K. Burke; M. Ernzerhof, Physical Review Letters 1997, 78 (7), 1396-1396.

[31] J. Klimeš; D.R. Bowler; A. Michaelides, Physical Review B 2011, 83 (19), 195131.

[32] C. Alexopoulos, A comprehensive review of methods for simulation output analysis. In Proceedings of the 38th conference on Winter simulation, Winter Simulation Conference: Monterey, California, 2006; pp 168-178.

[33] G.I. Csonka; J.P. Perdew; A. Ruzsinszky; P.H.T. Philipsen; S. Lebègue, et al., Physical Review B 2009, 79 (15), 155107.

[34] G.J. Janz, Thermodynamic and transport properties for molten salts : correlation equations for critically evaluated density, surface tension, electrical conductance, and viscosity data. Published by the American Chemical Society and the American Institute of Physics for the National Bureau of Standards: New York, United States. , 1988.

[35] G.J. Janz; C.B. Allen; N.P. Bansal; R.M. Murphy; R.P.T. Tomkins Physical Properties Data Compilations Relevant to Energy Storage: II Molten Salts: Data on Single and Multi-Component Salt Systems; National Bureau of Standards Report NSRDS-NBS 61 Part II: 1979.

[36] A. Jain; S.P. Ong; G. Hautier; W. Chen; W.D. Richards, et al., APL Materials 2013, 1 (1), -. 
[37] S. Cantor; J.W. Cooke; A.S. Dworkin; G.D. Robbins; R.E. Thoma, et al. Physical Properties of MoltenSalt Reactor Fuel, Coolant, and Flush Salts; Oak Ridge National Laboratory: 1968.

[38] D. Nevins; F.J. Spera; M.S. Ghiorso, American Mineralogist 2009, 94 (7), 975-980.

[39] M. Kumari; N. Dass, Physical Review B 1994, 49 (2), 844-848.

[40] J.K. Nørskov; J. Rossmeisl; A. Logadottir; L. Lindqvist; J.R. Kitchin, et al., The Journal of Physical Chemistry B 2004, 108 (46), 17886-17892.

[41] Y.-L. Lee; J. Kleis; J. Rossmeisl; D. Morgan, Physical Review B 2009, 80 (22), 224101.

[42] S.V. Alapati; J. Karl Johnson; D.S. Sholl, Physical Chemistry Chemical Physics 2007, 9 (12), 1438-1452.

[43] HSC Chemistry(R) 6.0. Outokumpu: 2002.

[44] P.L. Silvestrelli; A. Alavi; M. Parrinello; D. Frenkel, Physical Review B 1996, 53 (19), 12750-12760.

[45] NIST Chemistry WebBook, NIST Standard Reference Database Number 69, Eds. P.J. Linstrom and W.G. Mallard.

[46] P. Allen; D.J. Tildesley, Computer simulation of liquids. Clarendon Press: 1987.

[47] A. Thomas; M. Tam; W. Henry; M. Dane, New Journal of Physics 2014, 16 (1), 015018.

[48] J.A. Plambeck, Journal of Chemical and Engineering Data 1967, 12 (1), 77-\&.

[49] K.E. Johnson; Mackenzi.Jr, Journal of The Electrochemical Society 1969, 116 (12), 1697-\&.

[50] O. Shirai; H. Yamana; Y. Arai, Journal of Alloys and Compounds 2006, 408-412 (0), 1267-1273.

[51] K. Sridharan; T.R. Allen; M. Anderson; M. Simpson; L. Olson, et al. Thermal Properties of LiCl-KCl Molten Salt for Nuclear Waste Separation (NEUP Report); November 30th, 2012, 2012.

[52] P. Masset; D. Bottomley; R. Konings; R. Malmbeck; A. Rodrigues, et al., Journal of The Electrochemical Society 2005, 152 (6), A1109-A1115.

[53] Y. Castrillejo; M.R. Bermejo; E. Barrado; A.M. Martínez; P. Díaz Arocas, Journal of Electroanalytical Chemistry 2003, 545 (0), 141-157.

[54] S.P. Fusselman; J.J. Roy; D.L. Grimmett; L.F. Grantham; C.L. Krueger, et al., Journal of The Electrochemical Society 1999, 146 (7), 2573-2580.

[55] F. Lantelme; T. Cartailler; Y. Berghoute; M. Hamdani, Journal of The Electrochemical Society 2001, 148 (9), C604-C613.

[56] P. Masset; R.J.M. Konings; R. Malmbeck; J. Serp; J.-P. Glatz, Journal of Nuclear Materials 2005, 344 (1-3), 173-179. 
[57] R. Baboian; D.L. Hill; R.A. Bailey, Journal of The Electrochemical Society 1965, 112 (12), 1221-\&.

[58] R.O. Hoover; M. Shaltry; S. Phongikaroon; M.F. Simpson In Electrochemical Zirconium Recovery Experiments in Molten Salt System, International Pyroprocessing Research Conference, 2012.

[59] J.J. Roy; L.F. Grantham; D.L. Grimmett; S.P. Fusselman; C.L. Krueger, et al., Journal of The Electrochemical Society 1996, 143 (8), 2487-2492.

[60] C. Caravaca; G. Cordoba; M.J. Tomas In Electrochemical Study of Europium Trichloride in Molten Eutectic LiCl-KCl Actinide and Fission Product Partitioning \& Transmutation (Eighth Information Exchange Meeting), Las Vegas, Nevada, USA OECD-NEA: Las Vegas, Nevada, USA 2004.

[61] H.W. Jenkins; G. Mamantov; D.L. Manning, Journal of The Electrochemical Society 1970, 117 (2), 183-185.

[62] J.P. Perdew; A. Ruzsinszky; G.I. Csonka; O.A. Vydrov; G.E. Scuseria, et al., Physical Review Letters 2008, 100 (13), 136406.

[63] M. Sprik; G. Ciccotti, The Journal of Chemical Physics 1998, 109 (18), 7737-7744.

[64] W. Humphrey; A. Dalke; K. Schulten, Journal of Molecular Graphics 1996, 14 (1), 33-38.

[65] R. Shannon, Acta Crystallographica Section A 1976, 32 (5), 751-767.

[66] C. Hennig; J. Tutschku; A. Rossberg; G. Bernhard; A.C. Scheinost, Inorganic Chemistry 2005, 44 (19), 6655-6661.

[67] O. Pauvert; D. Zanghi; M. Salanne; C. Simon; A. Rakhmatullin, et al., The Journal of Physical Chemistry B 2010, 114 (19), 6472-6479.

[68] A.-L. Rollet; M. Salanne, Annual Reports Section "C" (Physical Chemistry) 2011, 107 (0), 88-123.

[69] N.D. Wood; R.A. Howe, Journal of Physics C: Solid State Physics 1988, 21 (17), 3177.

[70] Y. Okamoto; P.A. Madden, Journal of Physics and Chemistry of Solids 2005, 66 (2-4), 448-451.

[71] H. Matsuura; S. Watanabe; T. Sakamoto; T. Kanuma; K. Naoi, et al., Journal of Alloys and Compounds 2006, 408-412 (0), 80-83.

[72] Y. Okamoto; H. Motohashi, Zeitschrift Fur Naturforschung Section a-a Journal of Physical Sciences 2002, 57 (5), 277-280.

[73] Y. Okamoto; F. Kobayashi; T. Ogawa, Journal of Alloys and Compounds 1998, 271-273 (0), 355-358.

[74] Y. Okamoto; P.A. Madden; K. Minato, Journal of Nuclear Materials 2005, 344 (1-3), 109-114.

[75] F. Vaslow; A.H. Narten, The Journal of Chemical Physics 1973, 59 (9), 4949-4954.

[76] G.J. Janz; N.P. Bansal, Journal of Physical and Chemical Reference Data 1982, 11 (3), 505-693. 
[77] D. Yamada; T. Murai; K. Moritani; T. Sasaki; I. Takagi, et al., Journal of Alloys and Compounds 2007, 444-445 (0), 557-560.

[78] M. lizuka, Journal of The Electrochemical Society 1998, 145 (1), 84-88.

[79] C.H. Lee; K.H. Kang; M.K. Jeon; C.M. Heo; Y.L. Lee, Journal of The Electrochemical Society 2012, 159 (8), D463-D468.

[80] A. Leseur Commisariat a l'Énergie Atomique Commisariat a l'Énergie Atomique 1969.

[81] F. Caligara; L. Martinot; Duyckaer.G, Journal of Electroanalytical Chemistry 1968, 16 (3), 335-\&.

[82] L. Martinot; F. Caligara, Atomic Energy Review 1973, 11 (1), 3-61.

[83] B. Prabhakara Reddy; S. Vandarkuzhali; T. Subramanian; P. Venkatesh, Electrochimica Acta 2004, 49 (15), 2471-2478.

[84] C.E. Thalmayer; S. Bruckenstein; D.M. Gruen, Journal of Inorganic and Nuclear Chemistry 1964, 26 (2), 347-357. 